Nat. Hazards Earth Syst. Sci., 18, 2431-2453, 2018

https://doi.org/10.5194/nhess-18-2431-2018

(C) Author(s) 2018. This work is distributed under

the Creative Commons Attribution 4.0 License.

\title{
A comparison of building value models for flood risk analysis
}

\author{
Veronika Röthlisberger ${ }^{1,2,3}$, Andreas P. Zischg ${ }^{1,2,3}$, and Margreth Keiler $^{1,2}$ \\ ${ }^{1}$ Institute of Geography, University of Bern, Hallerstrasse 12, 3012 Bern, Switzerland \\ ${ }^{2}$ Mobiliar Lab for Natural Risks, University of Bern, Hallerstrasse 12, 3012 Bern, Switzerland \\ ${ }^{3}$ Oeschger Centre for Climate Change Research, University of Bern, Falkenplatz 16, 3012 Bern, Switzerland
}

Correspondence: Veronika Röthlisberger (veronika.roethlisberger@giub.unibe.ch)

Received: 13 December 2017 - Discussion started: 18 December 2017

Revised: 16 August 2018 - Accepted: 21 August 2018 - Published: 14 September 2018

\begin{abstract}
Quantitative flood risk analyses support decisions in flood management policies that aim for cost efficiency. Risk is commonly calculated by a combination of the three quantified factors: hazard, exposure and vulnerability. Our paper focuses on the quantification of exposure, in particular on the relevance of building value estimation schemes within flood exposure analyses on regional to national scales. We compare five different models that estimate the values of flood-exposed buildings. Four of them refer to individual buildings, whereas one is based on values per surface area, differentiated by land use category. That one follows an approach commonly used in flood risk analyses on regional or larger scales. Apart from the underlying concepts, the five models differ in complexity, data and computational expenses required for parameter estimations and in the data they require for model application.

The model parameters are estimated by using a database of more than half a million building insurance contracts in Switzerland, which are provided by 11 (out of 19) cantonal insurance companies for buildings that operate under a monopoly within the respective Swiss cantons. Comparing the five model results with the directly applied spatially referenced insurance data suggests that models based on individual buildings produce better results than the model based on surface area, but only if they include an individual building's volume.

Applying the five models to all of Switzerland produces results that are very similar with regard to the spatial distribution of exposed-building values. Therefore, for spatial prioritizations, simpler models are preferable. In absolute values, however, the five model results differ remarkably. The two simplest models underestimate the overall exposure, and even more so the extreme high values, upon which risk man-
\end{abstract}

agement strategies generally focus. In decision-making processes based on cost-efficiency, this underestimation would result in suboptimal resource allocation for protection measures. Consequently, we propose that estimating exposedbuilding values should be based on individual buildings rather than on areas of land use types. In addition, a building's individual volume has to be taken into account in order to provide a reliable basis for cost-benefit analyses. The consideration of other building features further improves the value estimation. However, within the context of flood risk management, the optimal value estimation model depends on the specific questions to be answered. The concepts of the presented building value models are generic. Thus, these models are transferable, with minimal adjustments according to the application's purpose and the data available. Within risk analyses, the paper's focus is on exposure. However, the findings also have direct implications for flood risk analyses as most risk analyses take the value of exposed assets into account in a linear way.

\section{Introduction}

Flood damage accounts for a large proportion of the economic losses due to natural hazards in developed countries, e.g. approximately one-third of losses over recent decades in Switzerland (Bundesrat, 2016) and Europe (European Environment Agency, 2017). Flood losses are expected to increase, not only due to ongoing anthropogenic climate change (IPCC, 2014) but also due to socio-economic development (Arnell and Gosling, 2016; Barredo, 2009; Kundzewicz et al., 2014; Liu et al., 2015). Future flood losses can be managed and ideally reduced with a wide range of 
measures. Yet, measures entail costs, either in the form of direct construction expenditures or, indirectly, through lost profits due to restricted land use. However, budgets are generally limited and thus they require measures be prioritized. This prioritization is based on quantitative flood risk analyses in many countries (Bründl et al., 2009; European Parliament, 2007).

In this context, risk is commonly defined as a combination of hazard, exposure and vulnerability (see Birkmann, 2013 for an overview). It is usually expressed as the expected annual damage within a given area. There are different approaches with which to estimate this expected annual damage. While models based on absolute damage functions combine exposure and vulnerability into one model component (e.g. Penning-Rowsell et al., 2005; Zhai et al., 2005), studies applying relative damage functions explicitly consider both the value and the physical vulnerability of exposed assets (e.g. Glas et al., 2017; Hatzikyriakou and Lin, 2017). The latter approach has the advantage of being more transparent than risk models with absolute damage functions. Our paper focuses on exposure, in particular on the relevance of building value estimation schemes within flood exposure analyses on regional to national scales. However, as most risk analyses take the value of exposed assets into account in a linear way, this study's results have direct implications for flood risk analyses, too.

Different studies (e.g. de Moel and Aerts, 2011; Koivumäki et al., 2010) show that uncertainties in quantitative flood risk analyses are driven rather by uncertainties in the value of exposed assets than by uncertainties in area or frequency of floods. This is especially true on regional to national scales, where data availability limits the spatial resolution and differentiation of asset values within flood exposure analyses. Aggregated classes of land use have been the norm (Gerl et al., 2016), at least until recently, and the area-specific value of each land use class is derived from lumped economic data of administrative units (Merz et al., 2010). This transformation of values per administrative unit into values per spatial unit differentiated by land use class implies spatial data disaggregation, also referred to as dasymetric mapping (Chen et al., 2004; Thieken et al., 2006). While several case studies investigate the influence that different data sources of asset values have on flood loss estimation (e.g. Bubeck et al., 2011; Budiyono et al., 2015; Cammerer et al., 2013; Jongman et al., 2012), the effect of dasymetric mapping methods is only addressed in a few publications. For instance, Wünsch et al. (2009) and Molinari and Scorzini (2017) show in local case studies that, even though the way in which exposed assets are estimated influences the resulting flood loss and thus flood risk, the spatial resolution of the exposed assets is more important. In both cases, the validation with recorded losses suggests that finer resolution of asset data improves the modelling results. Yet, both research teams conclude that further research on the impact of data resolution and disaggregation is needed. In fact, based on the growing availability of high-resolution data and increasing computational power, more and more flood-risk-related studies on national scales are based on data at the building level (e.g. Fuchs et al., 2015, 2017; Jongman et al., 2014; Röthlisberger et al., 2017). However, the individual monetary value of the buildings is usually not available due to data privacy restrictions and thus has to be estimated. There are different methods used in flood risk analyses to estimate individual building values (Jongman et al., 2014; Kleist et al., 2006). They range from uniform average value per building to sophisticated regression models considering different building features. Yet, the role of these value estimation methods in flood risk assessments has received even less attention than the effect of dasymetric mapping methods. To the best of our knowledge, no study has compared different object-based building value models, nor have these object-based methods ever been contrasted with the commonly used approaches of land-use-specific values per area within the context of regional or national risk analyses. To fill this gap, we investigate the influence of five different value estimation models (called M1 to M5; see Appendix A3 for an overview table of all abbreviations used in the text) on the resulting values of flood-exposed buildings in Switzerland. Four of these models (M1, M2, M4 and M5; see upper most row in Table 1) refer to individual buildings, whereas one model (M3) uses average values of buildings per area, differentiated by land use category. The five models' underlying concepts are widespread in risk management, construction industry and/or real estate management (see bottom row in Table 1). Apart from the concept, the five models mainly differ in their complexity and requirements on data resolution and differentiation.

However, this paper does more than evaluate the role of building value models within flood risk analyses. Our study also investigates the models' influence on flood risk management decisions. In the context of the above-mentioned need for prioritization, most current flood management policies aim for cost efficiency. With regard to cost-efficient measures, the actual monetary value of flood-exposed buildings is important, as are the statistical and spatial distributions of these values. While the spatial distributions suggest areas of priority for the implementation of cost-efficient protection measures, the monetary values of exposed buildings affect the upper cost limits of such measures. Thus, we investigate both the monetary values and their distributions. As for distributions and actual values, the extremely high values are particularly relevant for risk management. Therefore, our study analyses them in detail. The monetary values in this paper are insured values of buildings, which are replacement costs and correspond to the financial resources needed to reconstruct (flood) damaged buildings or building parts. Replacement costs are very common for cost-benefit analyses in Switzerland as the allocation of federal subsidies demands proof of the cost efficiency of measures using a tool with replacement values as default (Bründl et al., 2009). Moreover, a comprehensive review of flood loss models by Gerl 
Table 1. Overview of concepts, data and applications of the five investigated models for building value estimation. BFP stands for building footprint polygons, BZP for building zone polygons and PIC for points of insurance contracts.

\begin{tabular}{|c|c|c|c|c|c|}
\hline $\begin{array}{l}\text { Model name and } \\
\text { concept }\end{array}$ & $\begin{array}{l}\text { M } 1 \\
\text { uniform average value } \\
\text { per building }\end{array}$ & $\begin{array}{l}\text { M } 2 \\
\text { uniform average value } \\
\text { per building volume }\end{array}$ & $\begin{array}{l}\text { M } 3 \\
\text { average value of build- } \\
\text { ings per area, } \\
\text { differentiated by land } \\
\text { use category }\end{array}$ & $\begin{array}{l}\text { M } 4 \\
\text { average value per build- } \\
\text { ing volume, } \\
\text { differentiated by build- } \\
\text { ing features }\end{array}$ & $\begin{array}{l}\text { M } 5 \\
\text { value per building, } \\
\text { individually } \begin{array}{l}\text { calcu- } \\
\text { lated based on linear } \\
\text { regression }\end{array}\end{array}$ \\
\hline $\begin{array}{l}\text { Parameter estima- } \\
\text { tion and unit }\end{array}$ & $\begin{array}{l}\text { Total value of buildings } \\
\text { in an area divided by to- } \\
\text { tal number of buildings } \\
\text { in the same area, (CHF) }\end{array}$ & $\begin{array}{l}\text { Total volume of build- } \\
\text { ings in an area di- } \\
\text { vided by total number } \\
\text { of buildings in the same } \\
\text { area, }\left(\mathrm{CHF} \mathrm{m}^{-3}\right)\end{array}$ & $\begin{array}{l}\text { Total value of buildings } \\
\text { within an area of a par- } \\
\text { ticular land use category } \\
\text { divided by the size of } \\
\text { the area, }\left(\mathrm{CHF} \mathrm{m}^{-2}\right)\end{array}$ & $\begin{array}{l}\text { Total value of build- } \\
\text { ings with identical fea- } \\
\text { tures divided by the vol- } \\
\text { ume of the buildings, } \\
\left(\mathrm{CHF} \mathrm{m}^{-3}\right)\end{array}$ & $\begin{array}{l}\text { Minimal adequate linear } \\
\text { function of building fea- } \\
\text { tures, (CHF) }\end{array}$ \\
\hline \multicolumn{6}{|c|}{ Data for parameter estimation } \\
\hline $\begin{array}{l}\text { Minimal require- } \\
\text { ment }\end{array}$ & $\begin{array}{l}\text { Global sums of values } \\
\text { and numbers of build- } \\
\text { ings within a given area }\end{array}$ & $\begin{array}{l}\text { Global sums of values } \\
\text { and volumes of build- } \\
\text { ings within a given area }\end{array}$ & $\begin{array}{l}\text { Global sum of building } \\
\text { values within an area } \\
\text { with particular land use } \\
\text { size of the area }\end{array}$ & $\begin{array}{l}\text { Global sums of values } \\
\text { and volumes of build- } \\
\text { ings with identical fea- } \\
\text { tures }\end{array}$ & $\begin{array}{l}\text { Individual values and } \\
\text { features of buildings }\end{array}$ \\
\hline \multirow[t]{2}{*}{ Used in this study } & \multicolumn{3}{|c|}{$\begin{array}{l}\text { Complete data of eight cantons where entire portfolio } \\
\text { insurance data are available: }\end{array}$} & \multicolumn{2}{|c|}{$\begin{array}{l}\text { BFP of eleven cantons, reduced to polygons with } \\
\text { joined PIC and matching volumes } \\
(n=172562)\end{array}$} \\
\hline & $\begin{array}{l}\text { Total of insured build- } \\
\text { ings values in } 529224 \\
\text { PIC } \\
\text { Total number of BFP } \\
(391766)\end{array}$ & $\begin{array}{l}\text { Total of insured build- } \\
\text { ings values in } 529224 \\
\text { PIC } \\
\text { Total volume of BFP } \\
\left(653 \times 10^{6} \mathrm{~m}^{3}\right)\end{array}$ & $\begin{array}{l}\text { Total of insured build- } \\
\text { ings values in } 529224 \\
\text { PIC } \\
\text { BZP of } 12408 \mathrm{~km}^{2} \text {, } \\
\text { covering the entire area }\end{array}$ & $\begin{array}{l}\text { BFP including volume, } \\
\text { summarized value of } \\
\text { joined PIC and infor- } \\
\text { mation on land use and } \\
\text { building purpose }\end{array}$ & $\begin{array}{l}\text { BFP including volume, } \\
\text { summarized value } \\
\text { of joined PIC and } \\
\text { information on land } \\
\text { use, municipality type, } \\
\text { building purpose and } \\
\text { use }\end{array}$ \\
\hline $\begin{array}{l}\text { Data for bench- } \\
\text { mark selection }\end{array}$ & \multicolumn{5}{|c|}{$\begin{array}{l}\text { The data must be spatially referenced at object level and complete within a given area. } \\
\text { In this study, we use the } 529224 \text { PIC of the eight cantons, where complete portfolio data of the cantonal insurance company } \\
\text { for buildings are available. }\end{array}$} \\
\hline \multicolumn{6}{|c|}{ Data for model application } \\
\hline $\begin{array}{l}\text { Minimal require- } \\
\text { ment }\end{array}$ & $\begin{array}{l}\text { Individual buildings: lo- } \\
\text { cation only }\end{array}$ & $\begin{array}{l}\text { Individual buildings: lo- } \\
\text { cation and volume }\end{array}$ & $\begin{array}{l}\text { Land use: } \\
\text { spatially gapless infor- } \\
\text { mation on land use cat- } \\
\text { egories }\end{array}$ & $\begin{array}{l}\text { Individual buildings: } \\
\text { location, volume and featu }\end{array}$ & \\
\hline Used in this study & $\begin{array}{l}\text { BFP data set of } \\
2086411 \text { footprints }\end{array}$ & $\begin{array}{l}\text { BFP data set of } \\
2086411 \text { footprints, in- } \\
\text { cluding volume }\end{array}$ & $\begin{array}{l}\text { BZP of } 41290 \mathrm{~km}^{2} \text {, } \\
\text { covering the whole of } \\
\text { Switzerland }\end{array}$ & $\begin{array}{l}\text { BFP data set of } \\
2086411 \text { footprints, inclu } \\
\text { land use and building purp }\end{array}$ & $\begin{array}{l}\text { ding volume and information on } \\
\text { ose }\end{array}$ \\
\hline $\begin{array}{l}\text { Frequent fields of } \\
\text { applications }\end{array}$ & \multicolumn{2}{|c|}{$\begin{array}{l}\text { Default values in tools for cost-benefit } \\
\text { analyses of flood protection measures }\end{array}$} & $\begin{array}{l}\text { Widely used in flood } \\
\text { risk analyses on re- } \\
\text { gional to national scales }\end{array}$ & \multicolumn{2}{|c|}{$\begin{array}{l}\text { Mainly used in construction industry and real estate } \\
\text { management for the estimation of individual building } \\
\text { construction costs }\end{array}$} \\
\hline Examples & \begin{tabular}{l}
\multicolumn{2}{l}{ DEFRA (2001); Wage- } \\
naar et al. \\
van Dyck
\end{tabular} & $\begin{array}{l}\text { BAFU (2015); de Bruijn } \\
\text { et al. (2015); Mobiliar } \\
\text { Lab (2016); Winter et } \\
\text { al. (2018) }\end{array}$ & $\begin{array}{l}\text { de Bubeck et al. (2011); } \\
\text { Cammerer et al. (2013); } \\
\text { ICPR (2001); Klijn et } \\
\text { al. (2007); Thieken et } \\
\text { al. (2008) }\end{array}$ & $\begin{array}{l}\text { Hägi (1961); Naegeli } \\
\text { and Wenger (1997); } \\
\text { SVKG and } \\
\text { SEK/SVIT (2002) } \\
\text { Few applications in } \\
\text { flood risk manage- } \\
\text { ment, mainly at local } \\
\text { level, e.g. Arrighi et } \\
\text { al. (2013), }\end{array}$ & $\begin{array}{l}\text { Lowe et al. (2006); Son- } \\
\text { mez (2008) } \\
\text { To our knowledge no } \\
\text { application in flood risk } \\
\text { management }\end{array}$ \\
\hline
\end{tabular}

et al. (2016) shows that replacement costs are in fact the most often indicated cost base. Yet, there are risk analyses which use other types of building values, e.g. property prices (Ernst et al., 2010) or depreciated construction values (ICPR, 2001). However, this paper's topic, which is the relevance of the model approach for the resulting value of exposed buildings, does not depend on the value type and we thus refer to the literature (Merz et al., 2010; Penning-Rowsell, 2015) for broader discussions on building values in risk analyses.

\section{Methods applied and data used}

The data and methods section is organized as follows. The first subsection (Sect. 2.1) generically explains the set-ups of the five building values models and the estimation of their parameter values. In Sect. 2.2, we describe subsequent steps towards values of flood-exposed buildings, namely the intersection with flood hazard maps and the spatial aggregation of the results. The models are compared in Sect. 2.3. The data used in this study are described in the last part of this section, 
Sect. 2.4. Table 1 gives an overview of the five models with respect to their underlying concepts, data and applications.

\subsection{Model set-up for value estimation}

The five models in our study follow two different approaches. M3 is based on average value of buildings per area, differentiated by land use category. The other four models (M1, M2, M4 and M5) refer to individual buildings. These four models are defined as follows: M1 is uniform average value per building; M2 is uniform average value per building volume; M4 is average value per building volume, differentiated by building features; and M5 is value per building, individually calculated based on linear regression. From M1 to M5, the complexity of the five models increases, as well as the data and computational expenses required for the estimation of their parameter values (see Table 1). The selection of the five models is driven by the data, which are available throughout Switzerland, as this paper is focused on analyses on regional to national scales. An additional selection criteria is the current application in risk management, construction industry or real estate management (see bottom line in Table 1). In the following, we outline the concepts of the five models and the estimation of their parameter values.

\section{Model M1: uniform average value per building}

Model M1 takes a straightforward approach as it assigns the same uniform average building value to each building. The parameter estimation requires two quantities with the same spatial aggregation, e.g. administrative units: (1) the total cumulative value and (2) the total number of buildings within the same area. By dividing the total building value by the total number of buildings, we obtain the value of the model's only parameter. The parameter corresponds to the average value of the buildings situated within the observed area. The unit of the M1 parameter is monetary value per building, e.g. (CHF).

\section{Model M2: uniform average value per building volume}

Model M2 is based on the building volumes only. The data requirements for the parameter estimation are similar to the ones for M1. In place of the total number of buildings, M2 requires the total cumulative volume of buildings within a given area. To obtain the value of model's only parameter, the total building value is divided by the total building volume. Thus, the parameter of M2 is defined as the average value per building volume and is given in monetary value per unit volume, e.g. $\left(\mathrm{CHF} \mathrm{m}^{-3}\right)$.

\section{Model M3: average building values per area, differentiated by land use category}

Model M3 takes a very common approach to flood risk analyses on national scales. It makes use of average building val- ues per unit area, differentiated by land use category. For the same given area, the parameter estimation requires two comprehensive data sets of comparable spatial resolution: (1) gapless polygons of land use types and (2) spatially referenced data on building values. The two data sets are spatially joined, and the total building values per land use category are then calculated. In a last step, the cumulative building values per each type of land use are divided by the respective total area. This results in land-use-specific values of the model's parameter. They correspond to the average monetary building value per area of each land use category, which is given in monetary value per unit area, e.g. $\left(\mathrm{CHF} \mathrm{m}^{-2}\right)$.

\section{Model M4: average values per building volume, differentiated by land use category and building purpose}

Model M4's parameter is the same as in M2, i.e. the average monetary value per building volume. In contrast, the parameter values of M4 are not uniform but differentiated according to building feature. In this study, land use category and building purpose are the criteria for differentiation. To estimate the specific parameter values of M4, we combine data on monetary value, volume, land use category and building purpose at the building level. These assignments at building level require inputting data of high spatial resolution and precise localization. To estimate M4's parameter values, the data assignments have to be complete for each individual building. However, in contrast to M1, M2 and M3, the input data for M4 do not need to be comprehensive within a given area. For M4, only buildings with complete information on value, volume and the differentiation criteria are considered, and the value and volume of all buildings from the same combination of differentiation criteria (e.g. same land use category and building purpose) are summed up. Finally, the cumulated monetary values are divided by the respective volumes, resulting in the model's parameter values. Thus, we obtain one specific value for each combination of differentiation criteria. The parameter's unit is monetary value per unit volume, e.g. $\left(\mathrm{CHF} \mathrm{m}^{-3}\right)$.

\section{Model M5: value per building, individually calculated based on linear regression}

M5 is a linear regression model and is set up with the same input data as M4. We develop M5 in an exploratory manner by starting with a maximal model, which includes all available explanatory variables, i.e. building features (Table 1 and Table A1) and their interactions. It is then reduced to simpler models by removing non-significant interactions and variables. In addition, models with transformed variables are set up. Out of this variety of models, we select the minimal adequate model. Namely, we follow the principle of parsimony and choose a model with a relatively small Akaike Information Criterion (AIC; Akaike, 1974), a high coefficient of determination (adjusted $R^{2}$ ) and a minimal number 
of non-significant explanatory variables and interactions. In addition, we plot the model's residuals to check visually if principal assumptions of linear regression on residuals are satisfied. The result of this exploratory process is the minimal adequate model that makes it possible to calculate the expected monetary value of a building as a linear function of the selected buildings attributes and interactions. This value is given in monetary units, e.g. (CHF).

While the five applied models are conceptually different, the estimation of their parameter values in our study is based on the same data sets as much as possible. Nevertheless, the parameter estimation is based on two different kinds of data subsets. This is because the first three models (M1 to M3) require a data selection, which fulfils different criteria in comparison to the selection for M4 and M5. While the crucial prerequisite for M1, M2 and M3 is data completeness within a given area, the other two models require a high spatial accuracy of the input data, mirrored in matching data assignments on individual building levels. Figure 1 shows the workflow of the set-ups of the five models for building value estimation.

\subsection{Intersection with flood hazard maps and spatial aggregation}

Based on the five described models, it is possible to calculate the monetary value of individual buildings (M1, M2, M4 and M5) or mean building values within predefined areas (M3). To identify the values which are exposed to floods, the buildings or areas need to be spatially referenced and overlaid with flood hazard maps. The exposed values based on M3 are defined by the extent of flood-exposed areas and their respective monetary value per area. With regard to exposed values based on individual buildings, we classify a building as exposed to floods if it partially or entirely overlaps with a flood-prone area. From this exposed building, the entire monetary value is considered for the calculation of flood-exposed values. To compare the model based on areas (M3) with the other four models, we compile a map of regular hexagons with an area of $10 \mathrm{~km}^{2}$ and calculate the sum of exposed values per hexagon for all five models.

The described intersection with flood hazard zones reduces the value of exposure to the buildings within floodprone areas. In other contexts - in particular in the insurance industry, which provided data to this study (see Sect. 2.4.3) exposure includes all assets or buildings, irrespective of the object's individual chance of being damaged.

\subsection{Selection of benchmark model and model comparison}

Because our study mainly focuses on comparing different modelling approaches rather than on model predictions, we follow a benchmark test instead of a strict validation procedure. In a first step, we select a benchmark model that best fits the direct application of provided portfolio data of can- tonal insurance companies for buildings within eight Swiss cantons. In a second step, we compare the other four models with the benchmark model and examine the distributions of the extreme high values in more detail, including their spatial distributions. In contrast to the selection of the benchmark, the comparison of the benchmark model with the four other models covers the entire modelled area, i.e. the whole of Switzerland.

It is possible to select the model with the best fit in areas, where the data sets of the original building values are complete and spatially referenced on the building level. In our study, these areas correspond to the cantons, for which complete portfolio data of the cantonal insurance company for buildings are available; see Sect. 2.4.3. Within these cantons, we attribute the original building values from the portfolio data sets to the corresponding building geometries. Identifying flood-exposed buildings and summing the exposed values per hexagon are done in the same manner as for the buildingbased models. To identify the benchmark model, we examine differences and similarities between the model-based results and the results based on the original building values. For that matter, we calculate the root-mean-square errors (RMSE) and mean absolute errors (MAE) at the data aggregated to hexagons. We compile scatter plots of the hexagon values and compare the sum of exposed values over all hexagons within the validation area. As we are particularly interested in the distribution of the extreme high values, we further fit a generalized Pareto distribution (GPD) to the data above a certain consistent threshold. The threshold is the location parameter of the GPDs. The other two GPD parameters, the scale and shape, are estimated with the R package fExtremes (Wuertz, 2015) by applying the probability-weighted moment method. Furthermore, we compare the highest hexagon values of each data set within the validation area.

\subsection{Data}

Each of the five generic models makes it possible to estimate flood-exposed-building values based on data sets that are available in many countries. However, the model set-up, especially the estimation of the parameter values, requires data sets on monetary building values, which are either representative of a given area (M1 to M3) and/or spatially explicit (M3 to M5). In the following, Sect. 2.4.1, we present the input data of our study in Switzerland, and in Sect. 2.4.2 we detail the data selection for the parameter estimation. Section 2.4.3 shortly describes the data and area of model application and comparison.

\subsubsection{Input data}

The main three data sets which are used for the estimation of the model parameter values are (1) point of insurance contract (PIC), (2) building zone polygon (BZP) and (3) building footprint polygon (BFP). The latter two are also 


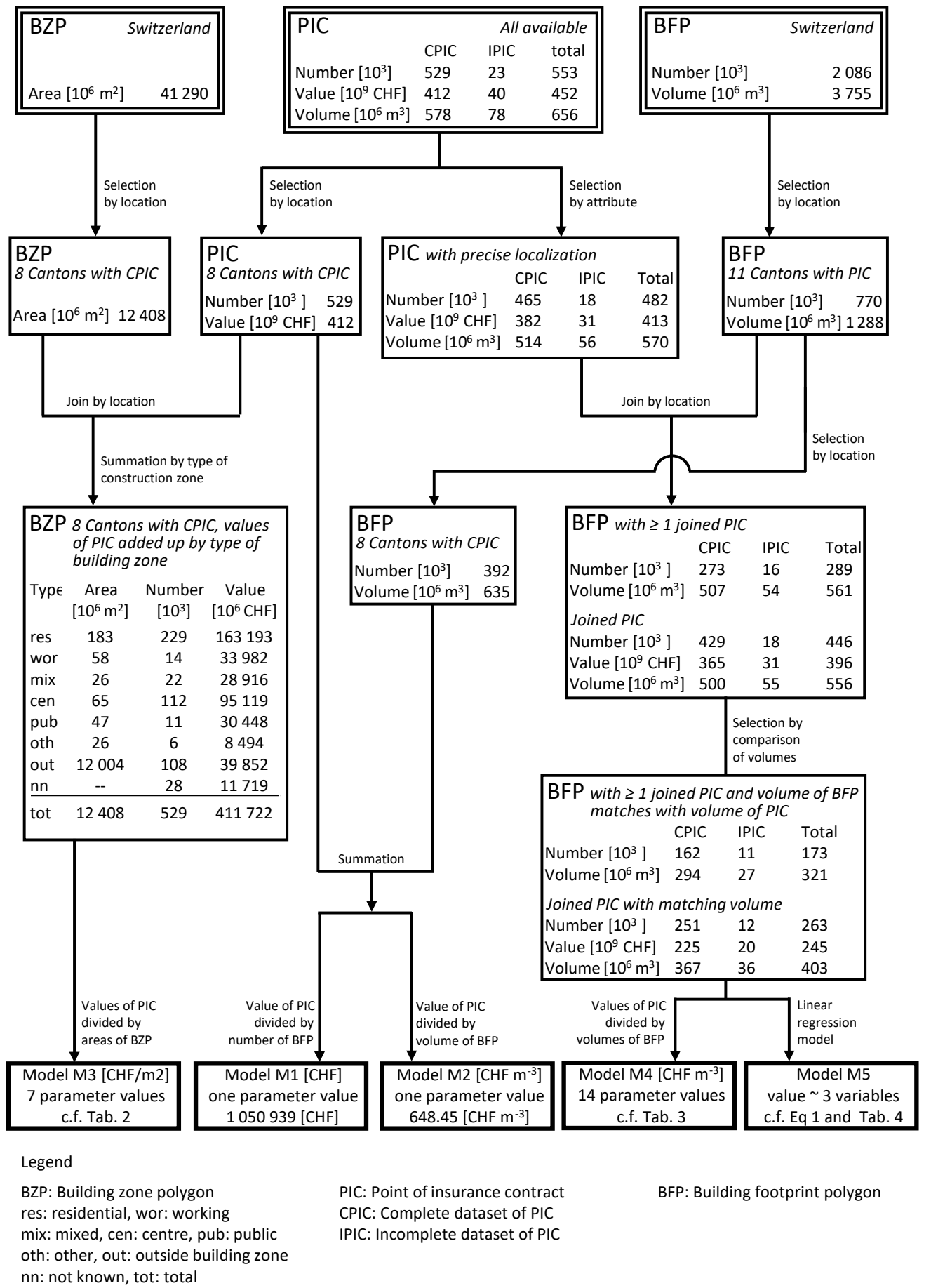

Figure 1. Workflow of the set-ups of the five investigated models for building value estimations.

used in the model application (see Table 1). The PIC data set is a compilation of 552698 insurance contracts provided by eleven cantonal insurance companies for buildings (see Fig. 2), harmonized and expressed as values as per 2014. Of these eleven insurance companies, eight companies provided the whole portfolio data set from 2013, whereas the three re- maining companies provided contract data, restricted to contracts, with at least one flood claim between 1999-2013 (two companies) and 1989-2013 (one company). All data are provided for the exclusive purpose of research and are subject to strict confidentiality. 


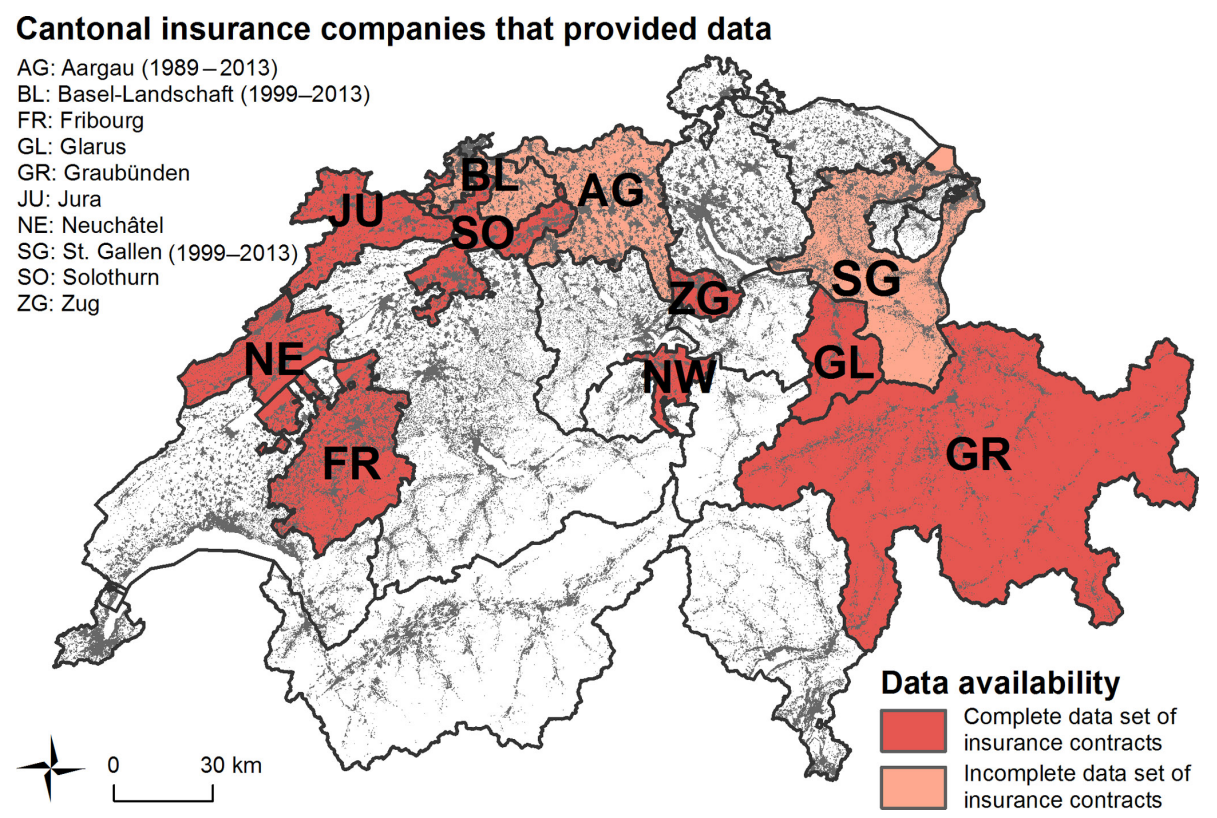

Figure 2. Overview of provided data by the cantonal insurance companies for buildings. Three insurance companies only provided data limited to contracts associated with at least one flood claim within the period indicated in brackets. The grey-shaded areas indicate the footprints of all buildings in Switzerland. Map source: Federal Office of Topography (swisstopo).

Table 2. Parameter values of the model M3, value per surface area $\left(\mathrm{CHF} \mathrm{m}^{-2}\right)$ of seven types of land use, i.e. six types of building zones and the area outside of building zones, based on a complete portfolio data of eight cantonal insurance companies for buildings in Switzerland. Insured values of buildings, which are localized at least on street level, are directly assigned to a type of land use. Values of the remaining buildings are split over all types of land use according to the size of the area of each type. The results per type of land use, which are used for further analyses, are in bold. Table entries are ordered by rank of these results.

\begin{tabular}{lrrrr}
\hline Type of land use & $\begin{array}{r}\text { Area } \\
\left(10^{3} \mathrm{~m}^{2}\right)\end{array}$ & $\begin{array}{r}\text { Value } \\
\left(10^{3} \mathrm{CHF}\right)\end{array}$ & $\begin{array}{r}\text { Value per area, directly assigned } \\
\left(\mathrm{CHF} \mathrm{m}^{-2}\right)\end{array}$ & $\begin{array}{r}\text { Value per area, total } \\
\left(\mathrm{CHF} \mathrm{m}^{-2}\right)\end{array}$ \\
\hline Centre & 64974 & 95118671 & 1463.94 & $\mathbf{1 4 6 4 . 8 8}$ \\
Mixed & 25705 & 28915610 & 1124.89 & $\mathbf{1 1 2 5 . 8 4}$ \\
Residential & 182593 & 163193242 & 893.76 & $\mathbf{8 9 4 . 7 0}$ \\
Public & 47323 & 30448192 & 643.42 & $\mathbf{6 4 4 . 3 6}$ \\
Working & 57652 & 33982269 & 589.44 & $\mathbf{5 9 0 . 3 8}$ \\
Others & 25593 & 8493504 & 331.87 & $\mathbf{3 3 2 . 8 1}$ \\
Outside building zone & 12003959 & 39851666 & -3.26 & $\mathbf{4 . 2 6}$ \\
Not directly assigned & - & 11719182 & 32.24 & 0.94 \\
\hline Total & 12407798 & 411722336 & & 33.18 \\
\hline
\end{tabular}

Cantonal insurance companies for buildings are present in 19 (of totally 26) Swiss cantons. In these 19 cantons, the insurance of buildings is compulsory and provided by the respective cantonal insurance company for buildings, which operates under a legal monopoly. The claims are compensated at replacement costs; thus, the premiums are calculated based on replacement values. Consequently, the portfolio data of a cantonal insurance company for buildings include the replacement value of virtually every building within the respective canton. In addition, most contracts are located on the building level - in this study, this is true for $87 \%$ of the provided contracts - and often contain the volume of the insured building or building part. In our case, $78 \%$ of the contracts include this information. The replacement values used and provided by the cantonal insurance companies for buildings are object-specific estimates by experts. The values are based either (for new buildings) on documented construction costs such as invoices or (for older buildings) on on-site inspection and validation.

The second input data are the countrywide harmonized BZPs, provided by the Federal Office for Spatial Development (see Table A1 in the Appendix A). For our analysis, 
Table 3. Parameter values of model M4, value per volume $\left(\mathrm{CHF} \mathrm{m}^{-3}\right)$ above ground, differentiated according to the area's land use where each building is located and by the purpose of the building. Calculations are based on insured values of 172562 buildings, which are provided by eleven cantonal insurance companies in Switzerland. Table entries are ordered by the value per building volume of buildings with a residential purpose.

\begin{tabular}{|c|c|c|c|c|c|c|}
\hline \multirow[b]{2}{*}{$\begin{array}{l}\text { Type of } \\
\text { land use }\end{array}$} & \multicolumn{3}{|c|}{ With residential purpose } & \multicolumn{3}{|c|}{ Without residential purpose } \\
\hline & $\begin{array}{l}\text { Insured building } \\
\text { values }\left(10^{3} \mathrm{CHF}\right)\end{array}$ & $\begin{array}{r}\text { Volume of } \\
\text { buildings }\left(10^{3} \mathrm{~m}^{3}\right)\end{array}$ & $\begin{array}{l}\text { Value per building } \\
\text { volume }\left(\mathrm{CHF} \mathrm{m}^{-3}\right)\end{array}$ & $\begin{array}{l}\text { Insured building } \\
\text { values }\left(10^{3} \mathrm{CHF}\right)\end{array}$ & $\begin{array}{r}\text { Volume of } \\
\text { buildings }\left(10^{3} \mathrm{~m}^{3}\right)\end{array}$ & $\begin{array}{l}\text { Value per building } \\
\text { volume }\left(\mathrm{CHF} \mathrm{m}^{-3}\right)\end{array}$ \\
\hline Public & 9684445 & 10150 & 954 & 7068467 & 8640 & 818 \\
\hline Others & 2322506 & 2446 & 950 & 866757 & 1187 & 730 \\
\hline Residential & 110421355 & 123056 & 897 & 2263843 & 2960 & 765 \\
\hline Centre & 56405627 & 65486 & 861 & 3452311 & 5351 & 645 \\
\hline Mixed & 15792658 & 19708 & 801 & 3107297 & 5321 & 584 \\
\hline Outside building zone & 9668384 & 16221 & 596 & 4908676 & 13062 & 376 \\
\hline Working & 7702381 & 15259 & 505 & 12140152 & 32234 & 377 \\
\hline
\end{tabular}

Table 4. Parameter estimates, standard errors, and $t$ and $p$ values of the three explanatory variables (and their pairwise interaction) of model M5. The three explanatory variables are residential purpose (ResPur) with values yes and no, the building volume above ground in $\mathrm{m}^{3}$ (volume) and land use (LaUse) with values residential, working, mixed, centre, public, others and outside (i.e. area outside building zones). The intercept stands for the variable values of $\log _{10}$ (volume $)=0$ (i.e. volume $=1 \mathrm{~m}^{3}$ ); ResPur=no and LaUse $=$ outside.

\begin{tabular}{lrrrr}
\hline Parameter & Estimate & Standard error & $t$ value & $\operatorname{Pr}(>|t|)$ \\
\hline Intercept & 3.097512 & 0.00633 & 489.334 & $<2.00 \mathrm{E}-16$ \\
ResPur yes & 0.793809 & 0.007992 & 99.323 & $<2.00 \mathrm{E}-16$ \\
$\log _{10}$ (volume) & 0.80819 & 0.002385 & 338.9 & $<2.00 \mathrm{E}-16$ \\
LaUse residential & -0.51207 & 0.009017 & -56.79 & $<2.00 \mathrm{E}-16$ \\
LaUse working & -0.4035 & 0.016537 & -24.4 & $<2.00 \mathrm{E}-16$ \\
LaUse mixed & -0.65351 & 0.015906 & -41.087 & $<2.00 \mathrm{E}-16$ \\
LaUse centre & -0.70887 & 0.009651 & -73.453 & $<2.00 \mathrm{E}-16$ \\
LaUse public & -0.44107 & 0.017177 & -25.678 & $<2.00 \mathrm{E}-16$ \\
LaUse others & -0.6658 & 0.027504 & -24.208 & $<2.00 \mathrm{E}-16$ \\
ResPur yes $\times \log _{10}$ (volume) & -0.15846 & 0.002694 & -58.815 & $<2.00 \mathrm{E}-16$ \\
ResPur yes $\times$ LaUse residential & -0.14691 & 0.003563 & -41.23 & $<2.00 \mathrm{E}-16$ \\
ResPur yes $\times$ LaUse working & -0.03614 & 0.005837 & -6.192 & $5.95 \mathrm{E}-10$ \\
ResPur yes $\times$ LaUse mixed & -0.05128 & 0.005654 & -9.071 & $<2.00 \mathrm{E}-16$ \\
ResPur yes $\times$ LaUse centre & -0.0001 & 0.003439 & -0.029 & 0.977 \\
ResPur yes $\times$ LaUse public & -0.17378 & 0.006391 & -27.19 & $<2.00 \mathrm{E}-16$ \\
ResPur yes $\times$ LaUse others & -0.07611 & 0.011406 & -6.673 & $2.52 \mathrm{E}-11$ \\
$\log _{10}$ (volume) $\times$ LaUse residential & 0.258569 & 0.003217 & 80.371 & $<2.00 \mathrm{E}-16$ \\
$\log _{10}$ (volume) $\times$ LaUse working & 0.158917 & 0.004704 & 33.787 & $<2.00 \mathrm{E}-16$ \\
$\log _{10}$ (volume) $\times$ LaUse mixed & 0.26366 & 0.004834 & 54.542 & $<2.00 \mathrm{E}-16$ \\
$\log _{10}$ (volume) $\times$ LaUse centre & 0.263382 & 0.003448 & 76.397 & $<2.00 \mathrm{E}-16$ \\
$\log _{10}$ (volume) $\times$ LaUse public & 0.256911 & 0.005323 & 48.262 & $<2.00 \mathrm{E}-16$ \\
$\log _{10}$ (volume) $\times$ LaUse others & 0.282637 & 0.009382 & 30.127 & $<2.00 \mathrm{E}-16$ \\
\hline & & & & \\
\hline
\end{tabular}

we reduce the nine provided building zone categories to six categories by merging the types "restricted building zones", "zones for tourism and sports" and "transport infrastructure within building zones" to the type "other building zones". Furthermore, we add the spatial complement of the building zones as "outside building zone" to the data set. Thus, we obtain a spatially gapless set of polygons with seven different types of building zones, namely "residential", "working", "mixed", "centre", "public", "others" and "outside building zone".
The third input data are data sets on buildings. In our study, we use the BFP of the swissTLM3D data set, provided by the Federal Office of Topography (see Table A1 in the Appendix A) and harmonized as outlined in Röthlisberger et al. (2017). Three of our building value models consider not only the BFP positions but also various attributes which we assign to the polygons in preprocessing steps as described in Appendix A1. The complete set of attributes considered in the model set-up consists of six items: (1) building volume above ground, (2) type of building zone, (3) type of municipality within which the BFP is located, (4 and 5) binary in- 


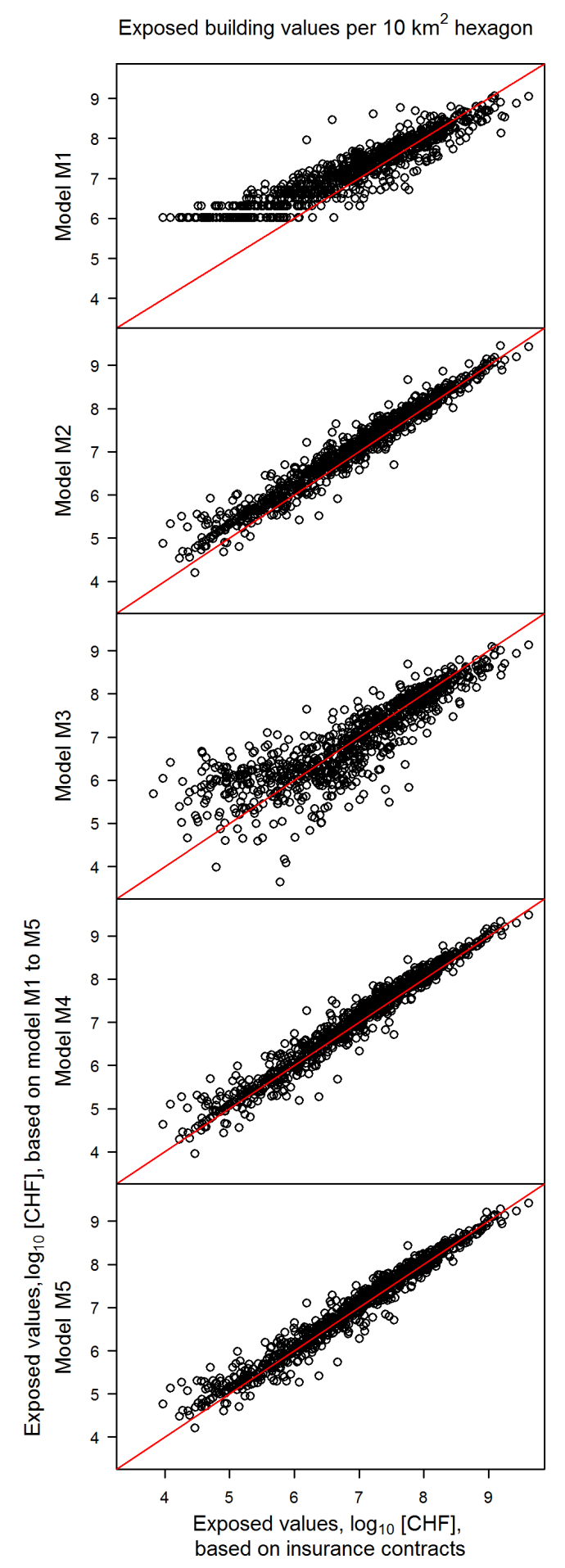

Figure 3. Scatter plot of flood-exposed-building values, aggregated to regular hexagons with a surface area of $10 \mathrm{~km}^{2}$. The sums based on models M1 to M5 ( $y$ axis) are plotted against the sums based on the direct application of the values from the spatially referenced building insurance contracts ( $x$ axis). The red lines indicate the $1: 1$ relation. The values are $\log _{10}$ transformed and sums below $10^{4} \mathrm{CHF}$ are not shown. formation about residential purpose and use and (6) building densities in the BFP's surroundings.

The calculation of flood-exposed-building values does not only require information on building values, but also on flood-prone areas. To define the areas potentially prone to inundation in Switzerland, we combine two different types of flood maps. The main source is a compilation of all available communal flood hazard maps in Switzerland (Borter, 1999; de Moel et al., 2009). These maps are collected, harmonized and provided in agreement with the responsible cantonal authorities by the Swiss Mobiliar Insurance Company. We use the maps of December 2016, which cover $72 \%$ of the buildings in Switzerland. In these maps, five different hazard levels are indicated, differentiated by the intensity (water depth and velocity) and probability of events (ARE et al., 2005). Out of the five hazard levels indicated in these maps, we consider the levels "major", "moderate" and "low" as flood-prone areas. With the selection of these three levels, we include events up to a return period of 300 years. For the $28 \%$ of the buildings in Switzerland that are not covered by the communal flood hazard maps, we use the coarser flood map called Aquaprotect. This data set is provided by the Federal Office for the Environment (Federal Office for the Environment, 2008). Aquaprotect is available for the whole of Switzerland and contains four different layers with recurrence periods of 50, 100, 250 and 500 years. For our study, we use the layer with the return period of 250 years. The compilation in GIS of the two map types follows the procedure described by Bernet et al. (2017) and results in a complete, nationwide map of flood-prone areas with return periods of up to 250 (territories not covered by communal hazard maps) and 300 years (territories covered by communal hazard maps).

\subsubsection{Data selection for the parameter estimation}

The workflow in Fig. 1 illustrates how the input data are combined and selected for the parameter estimation of the five models. The resulting data selection for each model is summarized in Table 1.

For M1 to M3, the two countrywide data sets (BFP for M1 and M2, BZP for M3) are reduced to the data entries, which are located within the eight cantons with complete building insurance data sets (left side of Fig. 1). In this way, the BZPs in the set-up of M3 cover $30 \%$ of the data's total coverage and the number of BFPs used for the parameter estimation of M1 and M2 correspond to $19 \%$ of the total number of BFPs in Switzerland.

The selection of PIC is made in two ways. For the first three models (M1 to M3), we select all PICs within the eight cantons where complete portfolio data sets are available (see Fig. 1: PIC all available $\rightarrow$ selection by location $\rightarrow$ PIC eight cantons with CPIC). For M1 and M2, we directly use the total insured building value of these 529224 contracts, which corresponds to CHF 412 billion. For M3, however, we fur- 
Table 5. Indicators for the comparison of model M1 and M5 with the direct application of insurance data (insured values according to pointreferenced building insurance contracts, PIC), in the eight cantons where complete portfolio data of the cantonal insurance companies for building are available. Sum represents the sum of exposed-building values over all $10 \mathrm{~km}^{2}$ hexagons, RMSE and MAE represent the rootmean-square error and the mean-absolute error of exposed-building values per hexagon when comparing M1 to M5 with PIC. The generalized Pareto distribution (GPD) is fitted for hexagons with exposed-building values higher than $10^{8} \mathrm{CHF}$, which is equal to the location parameter of the GPD. Shape and scale represent the respective parameter of the fitted GPD. Max represents the highest sum of exposed-building values per hexagon. Bold numbers indicate the value (of M1-M5) nearest to the value based on PIC.

\begin{tabular}{|c|c|c|c|c|c|c|}
\hline \multirow[t]{3}{*}{ Method } & \multicolumn{3}{|c|}{ Comparison over 1577 hexagons } & \multicolumn{3}{|c|}{ Comparison of extreme values } \\
\hline & \multirow[b]{2}{*}{ Sum } & \multirow[b]{2}{*}{ RMSE } & \multirow[b]{2}{*}{ MAE } & \multicolumn{2}{|c|}{$\begin{array}{l}\text { Fitted GPD for } \\
\text { hexagons }>10^{8}(\mathrm{CHF})\end{array}$} & \multirow[b]{2}{*}{ Max } \\
\hline & & & & Shape & Scale & \\
\hline & $\left(10^{6} \mathrm{CHF}\right)$ & $\left(10^{6} \mathrm{CHF}\right)$ & $\left(10^{6} \mathrm{CHF}\right)$ & & $\left(10^{6}\right)$ & $\left(10^{6} \mathrm{CHF}\right)$ \\
\hline M1 & 55667 & 124 & 23 & 0.25639 & 128 & 1163 \\
\hline M2 & 74451 & 73 & 14 & 0.44574 & 151 & 2874 \\
\hline M3 & 47880 & 115 & 21 & 0.31655 & 117 & 1367 \\
\hline M4 & 76956 & 52 & 12 & 0.43464 & 162 & 3127 \\
\hline M5 & 68111 & 60 & 11 & 0.44709 & 143 & 2682 \\
\hline PIC & 67375 & - & - & 0.49797 & 149 & 4157 \\
\hline
\end{tabular}

ther select the PICs that are localized at least at the street level, which is true for $95 \%$ of the PICs in the eight cantons with complete portfolio data. These PICs are spatially joined with the BZPs within the respective eight cantons. The monetary values of these PICs (CHF 400 billion total) are summarized per BZP type, and the values of the remaining PICs (i.e. CHF 12 million; see Fig. 1: BZP eight cantons with CPIC, values of PIC added up by type of building zone) are split proportionally to the area of each BZP category and added to the respective sum per BZP categories.

For M4 and M5, we reduce the original PIC data provided by eleven insurance companies to the $87 \%$ of points with a localization on building level, and then we assign these points to the nearest BFP with GIS software (see Fig. 1: PIC all available $\rightarrow$ selection by attribute $\rightarrow$ PIC with precise localization $\rightarrow$ join by location with BFP 11 cantons with PIC $\rightarrow$ BFP with $\geq 1$ joined PIC). $92 \%$ of the PICs with a localization on building level can be matched to a BFP within a distance of less than or equal to $5 \mathrm{~m}$. The attributes of these PICs, i.e. the replacement values and volumes of the insured buildings or building parts, are summarized per BFP. With this summation, the BFP with at least one joined PIC contains the attributes of the preprocessing steps (see description in Appendix A1), as well as the insurance-sourced building values and volumes. In particular, each of these BFPs includes two types of building volume. The first type is the volume above ground, calculated, in preprocessing steps, based on BFP area and the average height above ground of the building. The second type is the sum of volumes recorded in all PICs, which are assigned to the BFPs. For M4 and M5, we select only those BFPs for which the two mentioned volumes are within a predefined range (see Fig. 1: BFP with $\geq 1$ joined PIC $\rightarrow$ selection by comparison of volumes $\rightarrow$ BFP with $\geq 1$ joined PIC and volume of BFP matches with volume of PIC). For that matter, we calculate the volume ratio, i.e. the volume according to PIC divided by the BFP volume above ground. In the eight cantons, where we obtained complete portfolio data, we identify the volumes as matching if the volume ratio is equal to or more than 0.8 and less than or equal to 2.0. In the other three cantons, we set the lower criteria to equal to or more than 1.0. With this comparison of two independently derived volumes, we efficiently improve the quality of the BFP data. Particularly, we can exclude BFPs with inconsistencies in the calculation of the building volume above ground and BFPs with mistakenly (not) assigned PICs, which thus have monetary values that are too high (or low). The exclusion of these BFPs is crucial for the set-up of the regression model (M5) and cannot be done manually given the size of the data set. The described comparison of volumes reduces the BFPs and the joined PICs simultaneously and in a similar way. While $60 \%$ of the BFPs to which a PIC is assigned are finally used for the set-up of M4 and M5, the respective ratio of PICs amounts to $59 \%$.

\subsubsection{Data and area of model application and comparison}

The estimation of the parameter values for all five models is restricted to territories or buildings for which specified building insurance data are available. In contrast to the parameter estimation, applying the models does not require any insurance data and is thus feasible for any territories or buildings with attributes that correspond to the model parameters. In our study, the building referenced models (M1, M2, M4, M5) are applied to the entire BFP data set of 2086411 polygons, while M3 is applied to the countrywide BZP data set with an 
area of $41290 \mathrm{~km}^{2}$, thus covering all of Switzerland (see Table 1). The benchmark model is selected in the eight cantons where complete building insurance data sets are available; for the benchmark test, we again consider the entire territory of Switzerland.

\section{Results and discussion}

In this section, we first show the parameter values of the five building value models, M1 to M5 (Sect. 3.1), and then present the results of the benchmark selection and test. The overall discussion of the models in the last subsection (Sect. 3.4) complements the specific comments in the first three subsections.

\subsection{Parameter values}

\section{M1 and M2}

The parameter values of the two models with a single, uniform parameter are CHF 1050939 per building (M1) and 648.45 $\mathrm{CHF} \mathrm{m}^{-3}$ per volume above ground (M2). These values are rather high compared to international literature data (DEFRA, 2001; de Bruijn et al., 2015; Wagenaar et al., 2016), mainly because of comparatively high building standards and construction costs in Switzerland. For instance, Diaz Muriel (2008) finds that the price level index for construction in Switzerland is $20 \%$ higher than the average of the (at that time) $27 \mathrm{EU}$ member states. In addition to and in contrast with these other studies, we count attached buildings like terraced houses as only one building, and the parameter of M2 refers to the building volume above ground but includes the costs for underground building volumes too.

\section{M3 and M4}

Table 2 shows the parameter values of M3, i.e. the monetary values of buildings per surface area $\left(\mathrm{CHF} \mathrm{m}^{-2}\right)$ of seven land use categories. Most notable are the value differences between the areas inside and outside building zones. The value for the areas outside the building zones is only a very low percentage of the building zones' values, i.e. between $0.3 \%$ (for centre) and $1.3 \%$ (for others). Within the building zones, the values show less variation; i.e. they differ by a maximal factor of 4.5 corresponding to the difference between the categories others and centre. Two aspects determine the parameter value of a specific land use class in M3: firstly, the density (built volume per unit area) of buildings in this land use class and, secondly, the monetary value per built unit volume. The second aspect is at the core of model M4, and the respective parameter values by land use type and building purpose (with or without residential purpose) are presented in Table 3. The monetary value per volume is higher for buildings with a residential purpose than for non-residential buildings, ranging between $17 \%$ for residential and public building zones to
$58 \%$ for areas outside building zones. For residential buildings, the values for different land use types do not vary more than by a factor of 1.9 (working to public) and by a factor of up to 2.2 for buildings without a residential purpose. The ratio between the highest and the lowest M4 parameter value is 2.5. This is the ratio between the value per volume referring to residential buildings in public building zones and the value per volume, referring to non-residential buildings outside the building zone.

The remarkably smaller variation in parameter values in M4 compared to the variation in M3 and the differences between M3 and M4 in the ranking of land use types by parameter values all suggest that the differences in building densities have a much higher impact on the variation of M3 parameters than the differences in monetary value per volume. This is especially true for the areas outside building zones, where the M4 values per volume are comparable to the values within building zones. In contrast, the M3 parameter for the area outside building zones is not higher than $1.3 \%$ of the lowest value within building zones. That low percentage reflects a similarly low ratio between building densities outside and inside building zones. However, the effect of building densities also dominates within building zones. For the centre and mixed building zones, the M4 values per volume are at rank four and five, while the M3 parameter values for these zones are at rank one and two. That means the M3 values per area for the centre and mixed building zones are highly ranked, not because of high monetary values per built volume, but because these building zones are densely built-up. In contrast, comparing M3 and M4 parameter values for the public and other zones suggests that the construction costs for the buildings in these zones are comparably high, but the built volume per area is rather low. In the international literature, the monetary values of buildings per surface area (M3, e.g. Bubeck et al., 2011; ICPR, 2001; Kljin et al., 2007) and the construction costs per building volume (M4, e.g. Arrighi et al., 2013; Fuchs et al., 2015) are remarkably lower than the values in this study. As in the case of M1 and M2, these differences can be explained mainly by differences in building standards and construction costs in Switzerland (Diaz Muriel, 2008). For M3, the relatively dense settlements within building zones in Switzerland are another reason for the comparably high values in our study.

\section{Regression model M5}

Based on our data, the minimal adequate linear regression model for the estimation of building values is

$$
\begin{aligned}
\log _{10}(\text { value })= & \text { ResPur } \times \log _{10}(\text { volume })+\text { ResPur } \times \text { LaUse } \\
& +\log _{10}(\text { volume }) \times \text { LaUse },
\end{aligned}
$$

where value is the building value in (CHF), ResPur is the binary variable regarding residential purpose (yes/no), volume is the building volume above ground $\left(\mathrm{m}^{3}\right)$, and LaUse is the categorical variable regarding land use (six types of building 
Table 6. Hexagons of $10 \mathrm{~km}^{2}$ grouped in decreasing order of monetary values of flood-exposed buildings in Switzerland. For each group of hexagons and each model (M1 to M5) the following entities are reported: the lower limit of exposed-building values per hexagon (in $10^{6}$ $\mathrm{CHF})$, the sum $\left(\mathrm{S} *\right.$ in $\left.10^{9} \mathrm{CHF}\right)$ of exposed-building values over all hexagons of the respective group, and the percentage $(P *$ in $\%)$ of this sum per group in relation to the total value of flood-exposed buildings in Switzerland. The spatial distribution of six of these groups (highest $2 \%$, lowest $65 \%$ and four groups in between) are shown in Fig. 4.

\begin{tabular}{|c|c|c|c|c|c|c|c|c|c|c|c|c|c|c|c|c|}
\hline \multicolumn{2}{|c|}{ Hexagon group } & \multicolumn{5}{|c|}{$\begin{array}{c}\text { Lower limit }\left(10^{6} \mathrm{CHF}\right) \text { of } \\
\text { exposed-building values per hexagon }\end{array}$} & \multicolumn{10}{|c|}{$\begin{array}{l}\text { Monetary value of exposed buildings per hexagon group: } \\
\text { sum }\left[10^{9} \mathrm{CHF}\right] \text { and percentage }(\%) \text { of total }\end{array}$} \\
\hline \multirow[t]{2}{*}{ Share (\%) } & \multirow[t]{2}{*}{ Number } & \multirow[t]{2}{*}{ M1 } & \multirow[t]{2}{*}{ M2 } & \multirow[t]{2}{*}{ M3 } & \multirow[t]{2}{*}{ M4 } & \multirow[t]{2}{*}{ M5 } & \multicolumn{2}{|c|}{ M1 } & \multicolumn{2}{|c|}{ M2 } & \multicolumn{2}{|c|}{ M3 } & \multicolumn{2}{|c|}{ M4 } & \multicolumn{2}{|c|}{ M5 } \\
\hline & & & & & & & $\mathrm{S}^{*}$ & $P *$ & $\mathrm{~S}^{*}$ & $P *$ & $\mathrm{~S}^{*}$ & $P *$ & $S^{*}$ & $P *$ & $\mathrm{~S}^{*}$ & $P *$ \\
\hline 1 & 44 & 739 & 1518 & 827 & 1545 & 1409 & 48 & 14.1 & 112 & 21.9 & 57 & 18.4 & 127 & 23.6 & 107 & 22.8 \\
\hline 2 & 89 & 590 & 1057 & 585 & 1114 & 980 & 77 & 23.0 & 168 & 32.8 & 88 & 28.4 & 185 & 34.4 & 158 & 33.6 \\
\hline 5 & 222 & 353 & 550 & 344 & 565 & 500 & 137 & 40.8 & 268 & 52.4 & 146 & 47.0 & 287 & 53.5 & 248 & 52.8 \\
\hline 10 & 444 & 224 & 303 & 197 & 306 & 274 & 200 & 59.4 & 358 & 70.1 & 204 & 65.7 & 380 & 70.7 & 330 & 70.2 \\
\hline 20 & 889 & 108 & 129 & 88 & 134 & 119 & 270 & 80.3 & 447 & 87.3 & 264 & 85.2 & 471 & 87.8 & 412 & 87.5 \\
\hline 35 & 1555 & 41 & 38 & 27 & 38 & 34 & 317 & 94.1 & 496 & 97.0 & 299 & 96.5 & 523 & 97.3 & 457 & 97.2 \\
\hline 50 & 2222 & 12 & 7 & 5 & 6 & 6 & 333 & 99.0 & 509 & 99.6 & 308 & 99.5 & 536 & 99.7 & 469 & 99.7 \\
\hline 100 & 4444 & 0 & 0 & 0 & 0 & 0 & 336 & 100 & 511 & 100 & 310 & 100 & 537 & 100 & 470 & 100 \\
\hline
\end{tabular}

zones; see Sect. 2.4.1). The diagnostic plots of the model are presented in Appendix A2 and show that principal assumptions regarding the residuals are satisfied. The coefficient of determination, adjusted $R^{2}$, equals 0.88 . In other words, M5 explains $88 \%$ of the variance in the logarithmic monetary building values. The overall $F$ statistic $(60000$, on 21 and 172 degrees of freedom) results in a $p$ value $<2.2 \times 10^{-16}$, indicating an overall significance of the explanatory variables of M5. The estimates of the individual explanatory variables and their pairwise interactions are shown in Table 4, together with standard errors, $t$ and $p$ values. With one exception (ResPur yes $\times$ LaUse centre), all parameters of M5 are significant.

The intercept of $3.098(=\mathrm{CHF} 1250)$ refers to the variable values of $\log _{10}$ (volume $)=0$, i.e. volume $=1 \mathrm{~m}^{3}$, ResPur $=$ no and LaUse $=$ outside. If the same theoretical building of $1 \mathrm{~m}^{3}$ has a residential purpose, the estimation of the monetary value increases by a factor between 4.2 $\left(10^{(0.793-0.173)}\right)$ in public building zones and $6.2\left(10^{0.793}\right)$ outside building zones or in centre zones. As building volume increases, however, this factor between buildings with and without a residential purpose decreases and drops below 1 for building volumes between $8200 \mathrm{~m}^{3}$ (public building zones) and $102000 \mathrm{~m}^{3}$ (outside building zones). The effects of land use categories other than outside and their interaction with building volumes are similar to the ones with residential purposes, but in the opposite direction. A theoretical building with a volume of $1 \mathrm{~m}^{3}$ in a building zone has a lower building value by factors $0.18\left(10^{-(0.666+0.076)}\right.$ for other building zones, residential purpose) to $0.39\left(10^{-0.404}\right.$ for working zone, no residential purpose) compared to the same building outside building zones. With increasing building volumes, these factors increase and exceed 1 for building volumes between $52 \mathrm{~m}^{3}$ (public building zones, no res- idential purpose) and $584 \mathrm{~m}^{3}$ (working building zones, residential purpose). In any case, a higher volume of buildings results in a higher building value, but for all buildings with a residential purpose, the increase in value is lower than the increase in volume. Consequently, the ratio of difference in value to difference in volume for residential buildings within the same building zone is below 1 . In fact, the ratio ranges from $\Delta$ volume ${ }^{-0.350}$ for areas outside building zones to $\Delta$ volume ${ }^{-0.067}$ for other building zones. For nonresidential buildings, however, the increase in value is higher than the increase in volume in all building zones (with maximal ratio of $\Delta$ volume ${ }^{0.091}$ for other building zones), except for working building zone $\left(\Delta\right.$ value $=\Delta$ volume $\left.{ }^{-0.033}\right)$ and for areas outside building zones where the difference in value equals $\Delta$ volume ${ }^{-0.192}$.

In summary, variable values that are different from the intercept generally increase the resulting monetary building values in M5:

- For ResPur, buildings with a residential purpose have a higher value than non-residential buildings, at least up to a volume of several thousand cubic metres.

- For LaUse, buildings in building zones are more expensive than comparable buildings outside building zones, but only if the buildings have a minimal volume of several dozen to a few hundred cubic metres, depending on land use and building purpose.

- Higher building volumes result in higher monetary building values, and for non-residential buildings in five building zones (residential, mixed, centre, public and others) the increase in value is higher than the increase in volume.

The above statement on ResPur in M5 is consistent with the relation of residential to non-residential parameter values in 

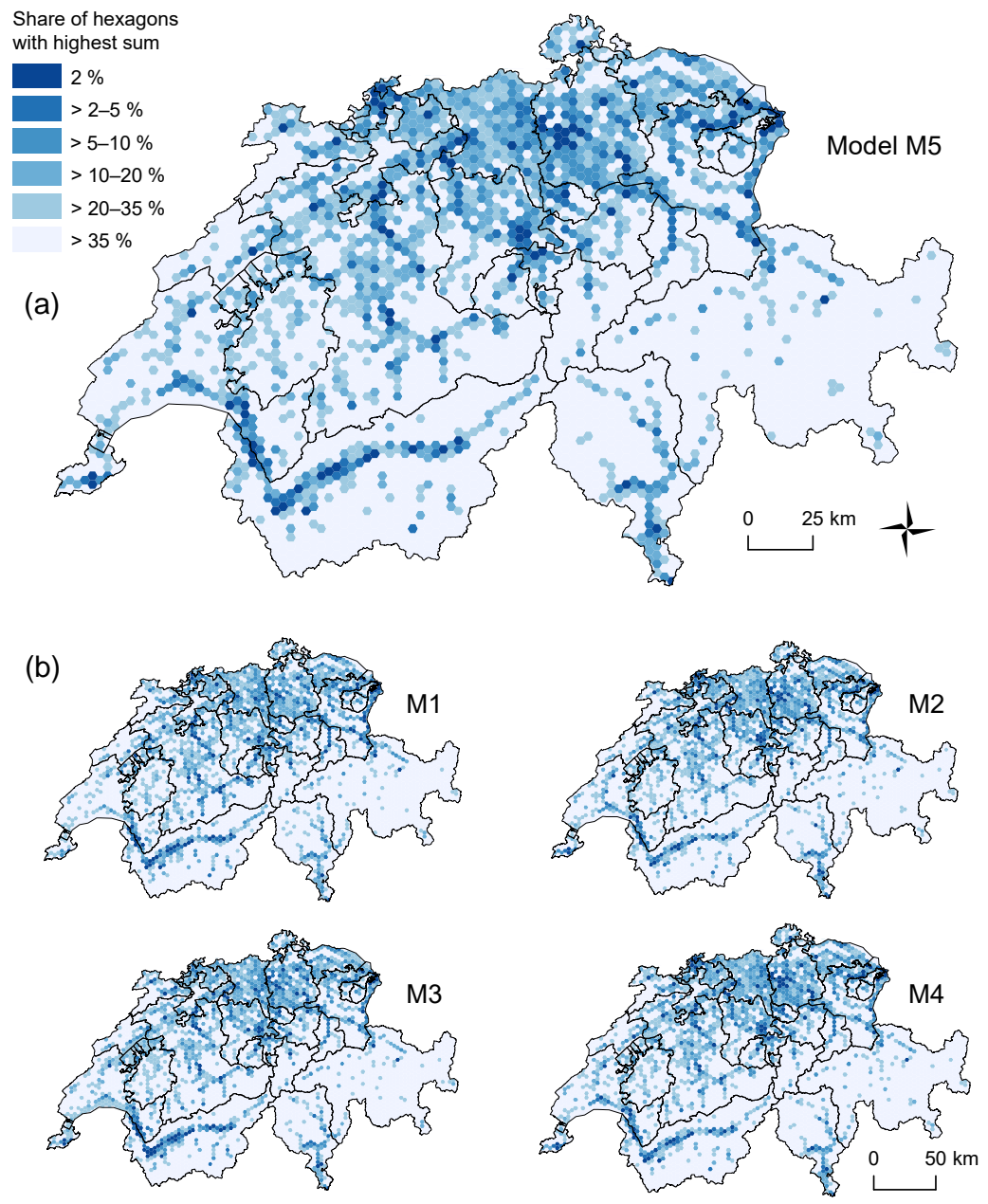

Figure 4. Spatial distribution of flood-exposed-building values based on benchmark model M5 (uppermost figure) in addition to models M1 to M4 (lower figures). Hexagons with a surface area of $10 \mathrm{~km}^{2}$ are categorized according to their sum of flood-exposed-building values. The specific limits of each category and the corresponding sums of exposed values are presented in Table 6. Map sources: Federal Office of Topography (swisstopo).

M4. M4 and M5 also agree in terms of LaUse, apart from working building zones. However, the findings on the different $\Delta$ volume to $\Delta$ value relations in M5 do not support the concept of a constant value per volume ratio, which is used in M4.

In the following, we summarize the main reasons for excluding originally considered building features (building densities, residential use and municipality types) and for logtransforming the building volumes and values. The buildings densities are all highly correlated with building volume, but they explain less of the building values' variance than the volume (lower adjusted $R^{2}$, higher AIC). The same holds for residential use with respect to residential purpose. Models that include municipality types and building zones contain many non-significant parameters. Models with municipality types (but without building zones) explain less than corresponding models with building zones (but without mu- nicipality types). The building volumes and values are $\log$ transformed since the untransformed values are right skewed and the residuals of models based on untransformed values are heteroscedastic.

\subsection{Comparison of models with direct application of insurance data for benchmark model selection}

The eight cantons with complete insurance portfolio data cover an area of $12408 \mathrm{~km}^{2}$. The corresponding layer of regular $10 \mathrm{~km}^{2}$ hexagons contains 1577 hexagons. Each point in Fig. 3 represents one of these hexagons. The $\log _{10}$ values of flood-exposed buildings summarized per hexagon based on value models M1 to M5 ( $y$ axis) are plotted against the exposed $\log _{10}$ values based on the direct application of the values in the spatially referenced building insurance contracts (PIC, $x$ axis). The red lines indicate a one-to-one relation. 
Table 7. Indicators for the comparison of model M1 to M4 with benchmark model M5. Sum represents the sum of exposed-building values over all hexagons, RMSE and MAE represent the root-mean-square error and the mean-absolute error of exposed-building values per hexagon when comparing M1 to M4 with M5. The generalized Pareto distribution (GPD) is fitted for hexagons with exposed-building values higher than $10^{8}(\mathrm{CHF})$, which is equal to the location parameter of the GPD. Shape and scale represent the respective parameter of the fitted GPD. Max represents the highest sum of exposed-building values per hexagon.

\begin{tabular}{|c|c|c|c|c|c|c|}
\hline \multirow[t]{3}{*}{ Model } & \multicolumn{3}{|c|}{ Comparison over 4444 hexagons } & \multicolumn{3}{|c|}{ Comparison of extreme values } \\
\hline & \multirow[b]{2}{*}{$\begin{array}{r}\text { Sum } \\
\left(10^{6} \mathrm{CHF}\right)\end{array}$} & \multirow[b]{2}{*}{$\begin{array}{r}\text { RMSE } \\
\left(10^{6} \mathrm{CHF}\right)\end{array}$} & \multirow[b]{2}{*}{$\begin{array}{r}\text { MAE } \\
\left(10^{6} \mathrm{CHF}\right)\end{array}$} & \multicolumn{2}{|c|}{$\begin{array}{l}\text { Fitted GPD for } \\
\text { hexagons }>10^{8}(\mathrm{CHF})\end{array}$} & \multirow[b]{2}{*}{$\begin{array}{r}\text { Max } \\
\left(10^{6} \mathrm{CHF}\right)\end{array}$} \\
\hline & & & & Shape & $\begin{array}{l}\text { Scale } \\
\left(10^{6}\right)\end{array}$ & \\
\hline M1 & 336460 & 214 & 47 & 0.20147 & 155 & 2912 \\
\hline M2 & 511208 & 52 & 15 & 0.41285 & 207 & 7546 \\
\hline M3 & 309794 & 191 & 44 & 0.30666 & 148 & 2634 \\
\hline M4 & 536989 & 65 & 15 & 0.43357 & 211 & 9102 \\
\hline M5 & 470420 & - & - & 0.42715 & 188 & 7201 \\
\hline
\end{tabular}

The exposure values per hexagon based on the M2, M4 and M5 models differ hardly by more than a factor of $10^{1}$ from the respective value based on direct PIC application. Moreover, the factors are homoscedastic. The results from M1 and $\mathrm{M} 3$, however, differ by up to a factor of $10^{2}$ from the ones based on direct insurance data application. In addition, the factors for small values are clearly bigger than the factors for high values. Moreover, in M1 the values of hexagons with only a few exposed buildings are generally overestimated, and the hexagons with one or two exposed buildings appear as two horizontal lines (at $1.05 \times 10^{6}$ and $2.1 \times 10^{6} \mathrm{CHF}$ ), with only seven hexagons in which the direct application of PIC results in higher exposure values than based on M1. In contrast, the values in hexagons with the most exposed buildings are underestimated in M1. Hexagons with high exposure values are underestimated by the other four value models too, although this is less pronounced in the cases of M2, M4 and M5 than in M1 and M3.

The data in Table 5 support these findings quantitatively. Overall, the indicators for the models M1 and M3 show the least agreement with the values based on directly applied PICs. The sum of exposed values over all 1577 hexagons is closest to the PIC-based result in M5 $(+1 \%)$, and the sum differs most in M3 $(-29 \%)$. M4 shows the least RMSE and M5 the least MAE, and for both indicators, the values of M1 and M3 are approximately twice as high as the ones of the other three models. Comparing extremely high values again shows a clear division into two groups: M2, M4 and M5 versus M1 and M3. The GPD fitted for hexagons with exposedbuilding values higher than $10^{8} \mathrm{CHF}$ show the best match with PIC-based extreme values for M2 and M5. The shape parameter determines the weight of the tail in the GPD, and it is highest in the case of direct PIC application, followed by the ones based on M5 $(-10.2 \%)$ and M2 $(-10.4 \%)$. This general underestimation of extremely high values by the five models is also reflected in the maximal exposure values, where the models result in $-25 \%$ (M4) to $-72 \%$ (M1) lower values compared to the direct PIC application.

Based on these results, we select M5 as the benchmark model for comparing the countrywide model applications presented in the following section.

\subsection{Benchmark test: differences and similarities between the five models}

The summarized value of all flood-exposed buildings in Switzerland is between $3.1 \times 10^{11}(\mathrm{M} 3)$ and $5.4 \times 10^{11} \mathrm{CHF}$ (M4). Based on the benchmark model M5, it is $4.7 \times$ $10^{11}$ CHF. The ratio between the highest and the lowest sums is thus 1.7 , and the ratios to the benchmark model are between 0.7 and 1.1. Table 6 presents the exposure values per eight ranked groups of the total 4444 regular hexagons covering Switzerland. The table demonstrates that, for all five models, the distributions of exposed values per hexagon are clearly right skewed, but for M1 and M3 the skewness is less pronounced. This skew to the right implies that the exposure values of a few $10 \mathrm{~km}^{2}$ hexagons represent an important part of the total value of flood-exposed buildings in Switzerland. For instance, the $2 \%$ (89) hexagons with the highest exposure values based on M5 contain flood-exposed buildings with a value of $1.6 \times 10^{11} \mathrm{CHF}$, which corresponds to $33.6 \%$ of the total value exposed in the whole of Switzerland based on M5. This share of exposed values in the 98th percentile is comparable for values from M2 $(32.8 \%)$ and M4 (34.4\%), but remarkably lower for M1 (23\%) and M3 (28.4\%). Comparing the absolute values of the most exposed hexagons results in the division of the same two clusters, down to the 95th percentile, the exposure values based on M2, M4 or M5 are approximately twice as high as the ones based on M1 or M3.

Figure 4 shows the spatial distribution of six ranked groups of hexagons for all five models. The group limits in exposed- 
Table 8. Overview of core features and suitable applications of the five models. Symbols of characteristics: + is positive, 0 is neutral and minus is negative. The key figure in the online version of the article is a graphical version of this table.

\begin{tabular}{|c|c|c|c|c|c|}
\hline Model name and concept & $\begin{array}{l}\text { M1 } \\
\text { uniform average } \\
\text { value per build- } \\
\text { ing }\end{array}$ & $\begin{array}{l}\text { M2 } \\
\text { uniform average } \\
\text { value per build- } \\
\text { ing volume }\end{array}$ & $\begin{array}{l}\text { M3 } \\
\text { average value } \\
\text { of buildings per } \\
\text { area, differenti- } \\
\text { ated by land use } \\
\text { category }\end{array}$ & $\begin{array}{l}\text { M4 } \\
\text { average value per } \\
\text { building volume, } \\
\text { differentiated by } \\
\text { building features }\end{array}$ & $\begin{array}{l}\text { M5 } \\
\text { value per build- } \\
\text { ing, individually } \\
\text { calculated based } \\
\text { on linear regres- } \\
\text { sion }\end{array}$ \\
\hline $\begin{array}{l}\text { Low data requirement for parameter estima- } \\
\text { tion }\end{array}$ & ++ & + & 0 & - & -- \\
\hline $\begin{array}{l}\text { Low computational expenses for parameter } \\
\text { estimation }\end{array}$ & ++ & ++ & + & + & -- \\
\hline Low data requirement for model application & + & - & ++ & -- & -- \\
\hline $\begin{array}{l}\text { Agreement with direct application of insur- } \\
\text { ance data }\end{array}$ & - & + & - & + & ++ \\
\hline \multicolumn{6}{|l|}{ Suitable applications at national level } \\
\hline Spatial distribution of exposed assets & ++ & & ++ & & \\
\hline Absolute values of exposed assets & & ++ & & ++ & ++ \\
\hline
\end{tabular}

building values per hexagon are presented in columns three to seven in Table 6 . The data again highlights the two groups: M2, M4 and M5 versus M1 and M3. However, the spatial distribution of the 1555 (35\%) hexagons with the highest exposure values is very similar, with each of the five applied value estimation models. These hexagons cover wide areas in the northern part of Switzerland, but appear as isolated points or lines only in the southern part. Overall, the pattern mirrors the spatial settlement structure (see Fig. 2) in Switzerland, but the areas in the west as well as in the most eastern canton (i.e. GR) seem to exhibit a disproportionally low exposure, which confirms results by Fuchs et al. (2017).

The log-log plots presented in Fig. 5 show the floodexposed values per hexagon based on the benchmark model M5 ( $x$ axis) against the values based on the other four models ( $y$ axis), with the red line indicating a one-to-one relation. In M2 and M4, the exposed values differ by not more than a factor of 5 from the respective values based on M5, whereas this factor goes up to $2 \times 10^{2}$ in M3 and to $5 \times 10^{1}$ for M1. In addition, for M1 and M3, the factors are clearly bigger for lower exposure values than for higher ones, and high values in both are generally underestimated. In contrast, the low exposure values in M1 are overestimated, and the values of hexagons with only a few exposed buildings appear as horizontal lines, similar to the pattern shown in the panel M1 of Fig. 3, as discussed above. The M2 panel suggests a general overestimation of the values compared to M5. Moreover, the differences are more pronounced for the middle ranges than for the extreme values. For the absolute deviations of M4 values from M5, no such dependency from the value's rank can be detected, but the low values are underestimated, while high values are overestimated in M4.
Table 7 presents indicators when the M5 benchmark model is compared with the other four models. Overall, these indicators suggest that M2, closely followed by M4, best matches M5. In contrast, the exposure values based on M1 and M3 both agree much less with the M5 results. Compared to M5, M1 and M3 show a general underestimation of floodexposed-building values, as well as an underestimation of the extreme high values. In contrast, M4 and, to a smaller degree, M2, overestimate the exposure values compared to M5. The parameters of the GPD fitted to hexagons with floodexposed-building values higher than CHF $10^{8}$ are very similar for M2, M4 and M5. Yet, the resulting empirical cumulative distribution functions presented in Fig. 6 for the highest two percent show that M2 matches better with M5 than M4.

\subsection{Overall discussion of the five models}

Based on the resulting values of flood-exposed buildings, the five models can be divided into two groups, one with M1 and M3 and another one with M2, M4 and M5 (see Table 8). Compared with the direct application of building values from PIC in eight cantons, M5 performs best. However, the results based on M2 and M4 are close, too, not only to the PIC results in the eight cantons (see Sect. 3.2), but also to the M5 results over all of Switzerland (see Sect. 3.3). These three high-performing models include the building volume to estimate the value, in contrast to M1 and M3. In other words, models which consider the building volume outperform the ones which do not include the volume, as long as there is a spread in the volume of the modelled building set.

With regard to data requirements for model parameter estimations (see Tables 1 and 8), M5 differs from the other four models, as it is the only model that needs data on an 


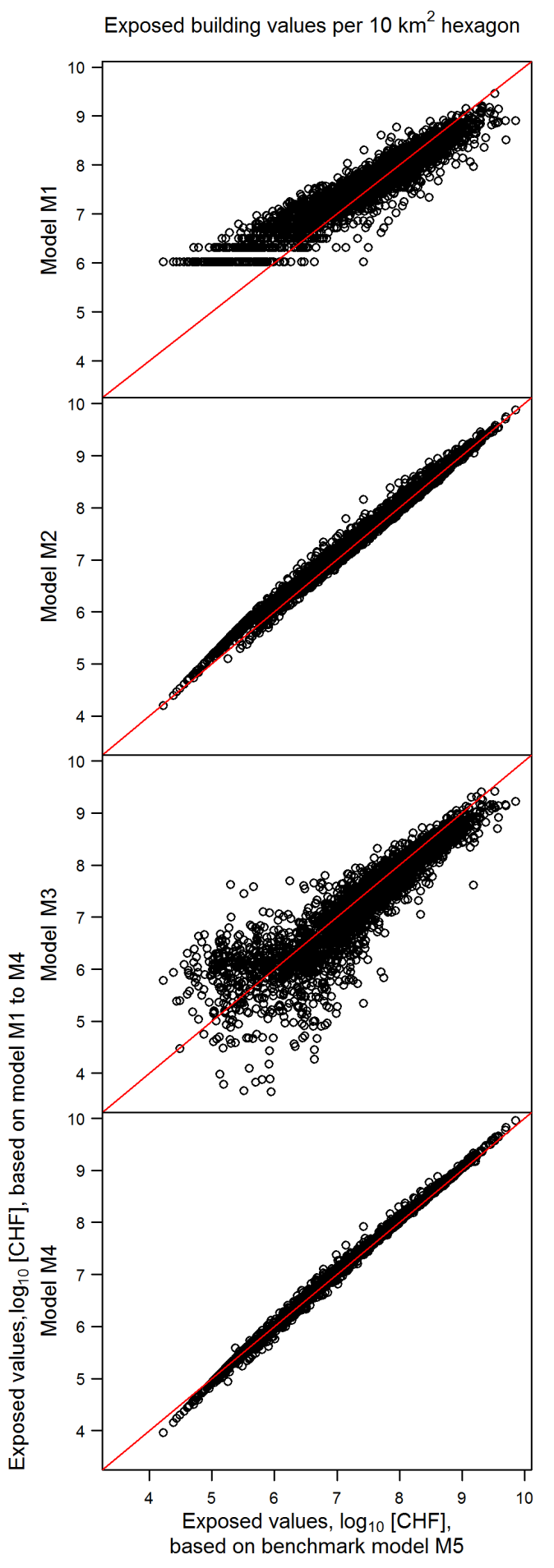

Figure 5. Scatter plot of flood-exposed-building values aggregated to regular hexagons with a surface area of $10 \mathrm{~km}^{2}$. The sums based on models M1 to M4 ( $y$ axis) are plotted against the sums based on the benchmark model M5 ( $x$ axis). The red lines indicate the $1: 1$ relation. All values are $\log _{10}$ transformed and sums below $10^{4} \mathrm{CHF}$ are not shown.

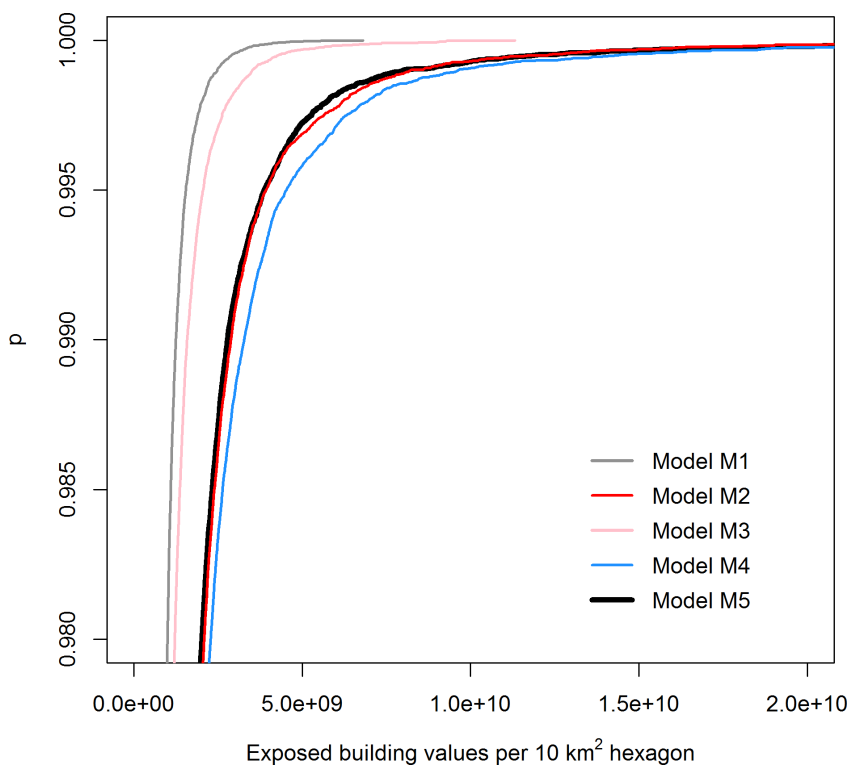

Figure 6. Empirical cumulative distribution function of floodexposed-building values aggregated to hexagons with a surface area of $10 \mathrm{~km}^{2}$. Cumulative probabilities $(p)$ are generated by $10^{5}$ random values from GPD with the parameters shown in Table 7. To improve the readability, only probabilities over $98 \%$ are shown.

individual building level. However, the less detailed data required in M1 to M4 differ too. While M1 and M2 require relatively simple data, i.e. global sums over a particular area such as administrative units, the sums of monetary building values required for M3 and M4 need to be differentiated to a higher degree. Consequently, the data requirements for the parameter estimation divide the models into three groups, with $\mathrm{M} 1$ and M2 in the group with the least requirements and M5 in the one with the most sophisticated requirements. The same grouping occurs when considering the computational expenses of the parameter estimations. While the parameter estimations in M1 and M2 each consist of one numerical division, and in M3 and M4 of several divisions, the set-up of a linear regression model in M5 is an iterative and timeconsuming process.

Grouping the models based on data requirements for the model application results in a distinction between M3 and the other four models (see Tables 1 and 8). Applying M3 requires spatially gapless data on land use, whereas the other four models need information on individual building levels for application. Among these four models, M1 requires the least information (location only), while M4 and M5 require the most information about each individual building, i.e. location, volume and other features. With regard to computational expenses for the model application, the five models are similar.

The overall comparison of the five models reveals several things (see Table 8). On the one hand, M5 has the best matching exposure values when compared to the direct application 
of existing individual building value. On the other hand, M5 requires the most data and computational resources. With M1 and $\mathrm{M} 3$, it is the opposite. In summary, all five models have advantages and disadvantages, and when selecting a model there is a need to balance them. However, selecting a model is often driven by data availability in real-world applications. As this study shows, selecting a model has consequences for resulting exposure values.

\section{Conclusions}

The paper illustrates the role of building value models in flood exposure analyses on regional to national scales. The presented findings are relevant for flood risk analyses too, as most risk analyses take the value of exposed assets into account in a linear way. The study is based on insurance data; the used monetary building values represent replacement costs. However, the insights of this paper into the relevance of the model approach for the resulting value of exposed buildings are valid as well for other value types, as depreciated construction costs or property prices.

With regard to the spatial distribution of exposed-building values, the models show widely uniform results. In contrast, the absolute values of exposure differ remarkably. The first finding implies that the spatial prioritization of flood protection measures would be similar with each of the applied value estimation methods. In practice, this means that the application of more sophisticated models does not generally provide a better basis for spatial prioritizations. Consequently, simpler models with lower requirements regarding data input and computational resources are preferable.

The second finding, however, suggests that decisionmaking processes that are based on cost-benefit criteria and thus rely on absolute monetary values are significantly influenced by which building value model one chooses. We find that models based on areas of land use classes, as commonly applied on regional to national scales, underestimate exposure values. The same is true for models based on individual buildings that do not take the building volumes into account. These two model types underestimate the overall exposure, but even more so the extremely high values on which risk management strategies generally focus. This underestimation of the exposure value by models not considering the volume of buildings indicates that flood-exposed buildings have in general a higher volume than buildings outside flood zones. By underestimating exposed values, the benefits of protection measures (i.e. avoided flood losses) are underestimated as well. In decision-making processes that are based on cost efficiency, this underestimation would result in suboptimal allocation of resources for protection measures. Consequently, we propose that estimating exposed-building values should be based on individual buildings rather than on areas of land use types. In addition, and provided that there is a spread in the volume of the modelled building set, the in- dividual volumes of buildings have to be taken into account in order to provide a reliable basis for cost-benefit analyses. The consideration of other building features further improves the value estimation.

In our study for the whole of Switzerland, with a data aggregation on $10 \mathrm{~km}^{2}$ hexagons, the optimal model for the estimation of absolute monetary building value is M5, i.e. a linear regression model considering the residential purpose and the building zone, in addition to building volume. In other contexts, where other data with different aggregations are available, the optimal building value model may be another one. For decisions that rely on absolute monetary building values, however, our results suggest using a value model based on individual building data that in any case includes the building volume. The concepts of the three respective value models presented in this study, i.e. M2, M4 and M5, are generic. Thus, these models are transferrable with minimal adjustments according to the application's purpose and the available data. However, within the context of flood risk management, the optimal value estimation model depends on the specific questions to be answered.

Growing availability of data with high resolution and spatial coverage in Switzerland and many other countries makes it possible to further develop complex multivariable building value models, e.g. based on machine learning methods as done by Wagenaar et al. (2017) for the modelling of absolute flood damage. Depending on future data availability, it is also possible to extend the presented analyses to other assets of interest such as population or infrastructure. The comparison between different nationwide exposure analyses based on object-specific data including monetary values would be another promising approach for further research.

Data availability. The data on which this study is based were provided by 11 different insurance companies. Each record contains confidential information on buildings such as the location (address and/or coordinates) and the insured value. Due to privacy protection, the data are subject to strict confidentiality and thus cannot be made accessible. 


\section{Appendix A}

\section{A1 Details on data and assignment of attributes to building polygons}

Table A1 presents details on the data sets, which we use in our study aside from the insurance data described in Sect. 2.4. We assign the attributes to the building footprint polygons as follows.

\section{A1.1 Building volume above ground}

The building volume above ground is the product of the BFP area times the average building height above ground. While the calculation of a polygon's area is a standard procedure in GIS, the estimation of the building height based on the available data is a multistep process. First, the points of the digital elevation model (swissALTI3D) and the digital surface model (DSM) are assigned to the polygons and for each polygon the two means of the assigned swissALTI3D points and DSM points are calculated. The subtraction of the mean of the DSM points from the mean from the swissALTI3D points results in the building's average height above ground. If this height is $\geq 3.5$ and $\leq 100 \mathrm{~m}$ (which is the case for 1378665 of total 2086411 BFPs) it is used in the volume calculation, otherwise $(n=707746)$ it is adjusted as follows: for residential buildings (i.e. buildings with assigned residential units as explained further down, $n=232016$ ) the average numbers of floors of the assigned BDS points (attribute GASTWS in BDS) is calculated, and for the first floor the height is set to $3.5 \mathrm{~m}$ and for each additional floor $2.5 \mathrm{~m}$ is added. For non-residential buildings with a height $<3.5 \mathrm{~m}$ or $>100 \mathrm{~m}(n=475730)$ the value is set to $3.5 \mathrm{~m}$.

\section{A1.2 Type of building zone and type of municipality}

For the assignment of the types of building zones and municipalities, the positions of the building polygons' centroids relative to the polygons in the data sets Bauzonen Schweiz and INFOFLAN-ARE are analysed. Prior to the assignment, in our study we reduce the types of building zones (attribute CH_BEZ_D in the data set Bauzonen Schweiz) from nine to seven types as described in Sect. 2.4.1. The types of municipalities (attribute TYP in INFOPLAN-ARE) are reduced from originally nine types down to six by merging the types "big centres" (code 1 in TYP), "secondary centres beside big centres" (2) and "middle centres" (4) to the type "big and middle centres" and by merging "belts of big centres" (3) and "belts of middle centres" (5) to the type "belts of big and middle centres". Furthermore, we add the areas of lakes to the type "agricultural" (code 8 in TYP) municipality if they are not part of a municipality but of a canton. We obtain a spatially gapless set of polygons with six types of municipality, namely "big and middle centres", "belts of big and middle centres", "small centres", "suburban rural municipal- ities", "agricultural municipalities and cantonal lake areas" and "tourist municipalities".

\section{A1.3 Binary information about residential purpose and use}

The point data of residential units in the BDS ( $n=1670540)$ are joined to the next BFP $(n=2086411)$ within $2 \mathrm{~m}$. Ninety-seven percent (1631531) of the BDS points lay in or within a distance of $2 \mathrm{~m}$ to a BFP. We consider a BFP as a building with residential purpose if at least one BDS point is assigned to it ( $n=1269908$ BFPs.) The criteria for residential use is that at least one person with main residence (attribute GAPHW in the BDS data set) is assigned to the building polygon, which is true for 1129904 BFPs.

\section{A1.4 Building densities in the BFP surroundings}

For the calculation of the building density in the surrounding of a BFP we define circles of 50,100, 200 and $500 \mathrm{~m}$ radius around the BFP's centroid. For each of these circles we calculate the area of all BFP (cut to the circle's edge) and divide it by the total area of the circle (cut to areas within Switzerland and not covered by lakes). This way, for each BFP we obtain the building density in a circle $50 \mathrm{~m}(100,200$ and $500 \mathrm{~m}$ ) around its centroid.

\section{A2 Diagnostic plots of linear regression model M5}

Figure A1 shows the diagnostic plots of M5, the minimal adequate linear regression model presented in Sect. 3.1. The two plots of residuals versus fitted values suggest (Fig. A1a and c) that residuals fulfil the assumptions of homoscedasticity, as the residuals are spread equally along the ranges of the fitted values. The quantile-quantile plot (Fig. A1b) indicates that the tales of the residuals' distribution are heavier than in a normal distribution. Cook's distance plot (Fig. A1d) shows that all buildings are inside Cook's distance of 0.5 , which means that no building significantly influences the resulting regression model. Overall it can be stated that the principal assumptions of linear regression modelling are reasonably satisfied.

\section{A3 Abbreviations used in the text}

Table A2 explains all abbreviations which are used in the text. 


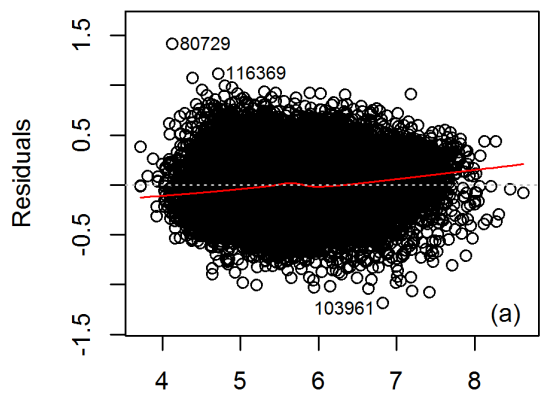

Fitted values

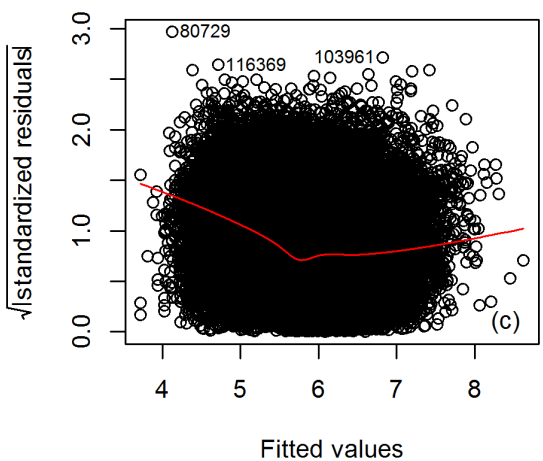

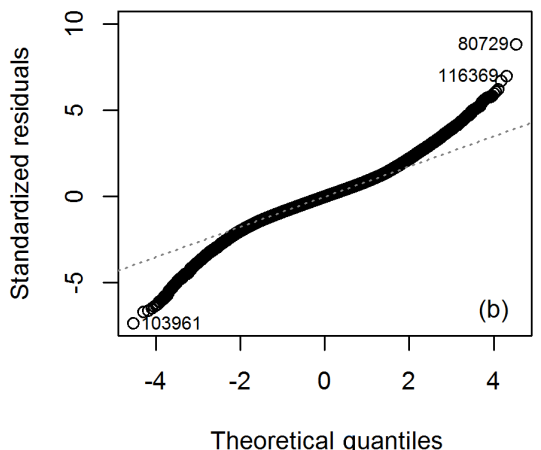

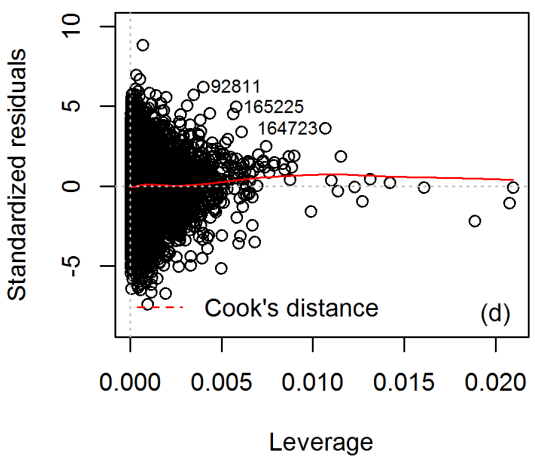

Figure A1. Diagnostic plots of model M5, namely residuals vs. fitted values (a), quantile-quantile plots of residuals vs. normally distributed quantiles (b), scale location plot (c) and Cook's distance plot (d).

Table A1. Summary of data used in the set-up and/or application of the five building value models. All links were last checked on 7 September 2018 .

\begin{tabular}{|c|c|c|c|c|c|}
\hline \multirow[t]{2}{*}{ Name } & \multicolumn{2}{|c|}{$\begin{array}{l}\text { Consideration in } \\
\text { model }\end{array}$} & \multirow[t]{2}{*}{ Data set } & \multirow[t]{2}{*}{ Description } & \multirow[t]{2}{*}{ Source } \\
\hline & set-up & application & & & \\
\hline $\begin{array}{l}\text { Building footprints } \\
\text { BFP }\end{array}$ & $\begin{array}{l}\text { M1, M2, } \\
\text { M4, M5 }\end{array}$ & $\begin{array}{l}\text { M1, M2, } \\
\text { M4, M5 }\end{array}$ & swissTLM3D & $\begin{array}{l}\text { Feature } \\
\text { TLM_GEBAEUDE_FOOTRPINT } \\
\text { of the Swiss topographical land- } \\
\text { scape model, v1.4, as of } 2016\end{array}$ & $\begin{array}{l}\text { Federal Office of Topography (swisstopo) https: } \\
\text { //shop.swisstopo.admin.ch/en/products/landscape/tlm3D }\end{array}$ \\
\hline $\begin{array}{l}\text { Polygons of build- } \\
\text { ing zones BZP }\end{array}$ & $\begin{array}{l}\text { M2, M3, } \\
\text { M4, M5 }\end{array}$ & $\begin{array}{l}\text { M2, M3, } \\
\text { M4, M5 }\end{array}$ & $\begin{array}{l}\text { Bauzonen Schweiz } \\
\text { (harmonized) }\end{array}$ & $\begin{array}{l}\text { Polygons of building zones, } 9 \text { har- } \\
\text { monized types, as of } 2012\end{array}$ & $\begin{array}{l}\text { Federal Office for Spatial Development (ARE) http://www. } \\
\text { kkgeo.ch/geodatenangebot/geodaten-bauzonen-schweiz.html }\end{array}$ \\
\hline $\begin{array}{l}\text { Digital elevation } \\
\text { model }\end{array}$ & $\begin{array}{l}\text { M2, M4, } \\
\text { M5 }\end{array}$ & $\begin{array}{l}\text { M2, M4, } \\
\text { M5 }\end{array}$ & swissALT3D & $\begin{array}{l}\text { High-precision digital elevation } \\
\text { model of Switzerland, grid size of } \\
2 \times 2 \mathrm{~m} \text {, as of } 2013\end{array}$ & $\begin{array}{l}\text { swisstopo https://shop.swisstopo.admin.ch/en/products/height_ } \\
\text { models/alti3D }\end{array}$ \\
\hline $\begin{array}{l}\text { Digital surface } \\
\text { model }\end{array}$ & $\begin{array}{l}\text { M2, M4, } \\
\text { M5 }\end{array}$ & $\begin{array}{l}\text { M2, M4, } \\
\text { M5 }\end{array}$ & DSM & $\begin{array}{l}\text { Digital surface model, density of } \\
1 \text { point per } 2 \mathrm{~m}^{2} \text {, last updated in } \\
2008\end{array}$ & $\begin{array}{l}\text { swisstopo https://shop.swisstopo.admin.ch/en/products/height_ } \\
\text { models/DOM }\end{array}$ \\
\hline Municipality types & M4, M5 & & INFOPLAN-ARE & $\begin{array}{l}\text { Typology of municipalities ARE, } \\
\text { nine types based on municipality } \\
\text { typology of FSO, as of } 2014\end{array}$ & $\begin{array}{l}\text { ARE, Federal Statistical Office (FSO) and swisstopo data.geo. } \\
\text { admin.ch/ch.are.gemeindetypen/data.zip }\end{array}$ \\
\hline $\begin{array}{l}\text { Residential purpose } \\
\text { of buildings }\end{array}$ & M4, M5 & M4, M5 & BDS & $\begin{array}{l}\text { No. of residential units in the } \\
\text { Buildings and Dwellings statistics } \\
\text { BDS, as of } 2012\end{array}$ & $\begin{array}{l}\text { FSO https://www.bfs.admin.ch/bfs/en/home/statistics/ } \\
\text { construction-housing/surveys/gws2009.assetdetail.8521.html }\end{array}$ \\
\hline $\begin{array}{l}\text { Residential use of } \\
\text { buildings }\end{array}$ & M4, M5 & & BDS & $\begin{array}{l}\text { No. of people with main residence } \\
\text { in BDS; see residential purpose }\end{array}$ & see residential purpose \\
\hline Area of cantons & $\begin{array}{l}\text { M1, M2, } \\
\text { M3 }\end{array}$ & & $\begin{array}{l}\text { SwissBOUN- } \\
\text { DARIES3D }\end{array}$ & $\begin{array}{l}\text { Polygons of the } 26 \text { Swiss cantons } \\
\text { (districts), as of } 2016\end{array}$ & $\begin{array}{l}\text { swisstopo https://shop.swisstopo.admin.ch/en/products/ } \\
\text { landscape/boundaries3D }\end{array}$ \\
\hline
\end{tabular}


Table A2. Abbreviations used in the text in alphabetical order.

\begin{tabular}{ll}
\hline Abbreviation & Meaning \\
\hline AIC & Akaike Information Criterion \\
BFP & Building footprint polygon \\
BZP & Building zone polygon \\
CPIC & Complete data set of points of insurance contracts \\
M1 & Model M1, uniform average value per building \\
M2 & Model M2, uniform average value per building volume \\
M3 & Model M3, average values per area, differentiated by land use category \\
M4 & Model M4, average values per building volume, differentiated by land use category and building purpose \\
M5 & Model M5, value per building, individually calculated based on linear regression \\
MAE & Mean absolute error \\
PIC & Point of insurance contract \\
RMSE & Root-mean-square error \\
swistLM3D & Swiss topographical landscape model \\
\hline
\end{tabular}


Author contributions. VR and APZ designed the models and the computational framework and analysed the data. All authors discussed the results and contributed to the manuscript outline. VR wrote the manuscript with input from all authors. MK supervised the project.

Competing interests. The last author is a member of the editorial board of the journal. Otherwise, the authors declare that they have no conflict of interest.

Acknowledgements. We thank the natural hazards group at the Swiss Mobiliar Insurance Company "die Mobiliar AG" for acquiring and compiling the communal flood hazard maps. Furthermore, we would like to thank the public insurance companies for buildings of the cantons Aargau, Basel-Landschaft, Fribourg, Glarus, Graubünden, Jura, Neuchâtel, Nidwalden, St. Gallen, Solothurn and Zug for providing building-specific data and supporting us during the data harmonization process. Also, we would like to thank the Federal Office of Topography, the Federal Office for Spatial Development, the Federal Office for the Environment and the Federal Statistical Office for providing the corresponding spatial data. We thank Daniel Bernet for the joint effort in collecting and harmonizing the insurance data and for proofreading, Markus Mosimann for his support harmonizing the insurance data and Craig Hamilton for language editing. Last but not least, we would like to thank the two anonymous reviewers and the editor for their inputs which substantially improved this manuscript.

Edited by: Thomas Glade

Reviewed by: two anonymous referees

\section{References}

Akaike, H.: A new look at the statistical model identification, IEEE T. Automat. Contr., 19, 716-723, 1974.

ARE Bundesamt für Raumplanung, BWG, Bundesamt für Wasser und Geologie, and BUWAL, Bundesamt für Umwelt, Wald und Landschaft: Empfehlung Raumplanung und Naturgefahren, 50 pp., 2005.

Arnell, N. W. and Gosling, S. N.: The impacts of climate change on river flood risk at the global scale, Climatic Change, 134, 387401, https://doi.org/10.1007/s10584-014-1084-5, 2016.

Arrighi, C., Brugioni, M., Castelli, F., Franceschini, S., and Mazzanti, B.: Urban micro-scale flood risk estimation with parsimonious hydraulic modelling and census data, Nat. Hazards Earth Syst. Sci., 13, 1375-1391, https://doi.org/10.5194/nhess13-1375-2013, 2013.

BAFU Bundesamt für Umwelt: EconoMe 4.0 Wirksamkeit und Wirtschaftlichkeit von Schutzmassnahmen gegen Naturgefahren: Handbuch/Dokumentation, available at: https://econome.ch/eco_ work/doc/Handbuch_EconoMe_4.0_Version_Dez2016_D.pdf (last access: 7 September 2018), 2015.

Barredo, J. I.: Normalised flood losses in Europe: 19702006, Nat. Hazards Earth Syst. Sci., 9, 97-104, https://doi.org/10.5194/nhess-9-97-2009, 2009.
Bernet, D. B., Prasuhn, V., and Weingartner, R.: Surface water floods in Switzerland: what insurance claim records tell us about the damage in space and time, Nat. Hazards Earth Syst. Sci., 17, 1659-1682, https://doi.org/10.5194/nhess-17-1659-2017, 2017.

Birkmann, J.: Risk, in: Encyclopedia of Natural Hazards, edited by: Bobrowsky, P. T., Springer, Dordrecht, 856-862, 2013.

Borter, P.: Risikoanalyse bei gravitativen Naturgefahren: Methode, Umwelt-Materialien, Nr. 107/I, 117 pp., 1999.

Bründl, M., Romang, H. E., Bischof, N., and Rheinberger, C. M.: The risk concept and its application in natural hazard risk management in Switzerland, Nat. Hazards Earth Syst. Sci., 9, 801813, https://doi.org/10.5194/nhess-9-801-2009, 2009.

Bubeck, P., de Moel, H., Bouwer, L. M., and Aerts, J. C. J. H.: How reliable are projections of future flood damage?, Nat. Hazards Earth Syst. Sci., 11, 3293-3306, https://doi.org/10.5194/nhess11-3293-2011, 2011.

Budiyono, Y., Aerts, J., Brinkman, J., Marfai, M. A., and Ward, P.: Flood risk assessment for delta mega-cities: A case study of Jakarta, Nat. Hazards, 75, 389-413, https://doi.org/10.1007/s11069-014-1327-9, 2015.

Bundesrat: Umgang mit Naturgefahren in der Schweiz - Bericht des Bundesrates, Bern, 131 pp., 2016.

Cammerer, H., Thieken, A. H., and Lammel, J.: Adaptability and transferability of flood loss functions in residential areas, Nat. Hazards Earth Syst. Sci., 13, 3063-3081, https://doi.org/10.5194/nhess-13-3063-2013, 2013.

Chen, K., McAneney, J., Blong, R., Leigh, R., Hunter, L., and Magill, C.: Defining area at risk and its effect in catastrophe loss estimation: A dasymetric mapping approach, Appl. Geogr., 24, 97117, https://doi.org/10.1016/j.apgeog.2004.03.005, 2004.

de Bruijn, K. M., Wagenaar, D. J., Slager, K., de Bel, M., and Burzel, A.: Updated and improved method for flood damage assessment: SSM2015, Version 2, Rijkswaterstaat Water, Verkeer en Leefomgeving, 1220043-003, 125 pp., 2015.

de Moel, H. and Aerts, J. C. J. H.: Effect of uncertainty in land use, damage models and inundation depth on flood damage estimates, Nat. Hazards, 58, 407-425, https://doi.org/10.1007/s11069-0109675-6, 2011.

de Moel, H., van Alphen, J., and Aerts, J. C. J. H.: Flood maps in Europe - methods, availability and use, Nat. Hazards Earth Syst. Sci., 9, 289-301, https://doi.org/10.5194/nhess-9289-2009, 2009.

DEFRA, Departement for Environment, Food and Rual Affairs: National Appraisal of Assets at Risk from Flooding and Coastal Erosion, including the potential impact of climate change: Final Report, Flood Management Division, London, 64 pp., 2001.

Diaz Muriel, C.: Wide spread in construction prices across Europe in 2007, Statistics in focus 114, eurostat, 2008.

Ernst, J., Dewals, B. J., Detrembleur, S., Archambeau, P., Erpicum, S., and Pirotton, M.: Micro-scale flood risk analysis based on detailed 2D hydraulic modelling and high resolution geographic data, Nat. Hazards, 55, 181-209, https://doi.org/10.1007/s11069010-9520-y, 2010.

European Environment Agency: Economic losses from climaterelated extremes, IND-182-en, CSI042, CLIM 039, 16 pp., 2017.

European Parliament: Directive 2007/60/EC of the European Parliament and of the Council of 23 October 2007 on the assessment and management of flood risk: 2007/69/EC, 8 pp., 2007. 
Federal Office for the Environment: Terms of Use Aquaprotect, available at: https://www.bafu.admin.ch/ bafu/de/home/themen/naturgefahren/fachinformationen/ naturgefahrensituation-und-raumnutzung/gefahrengrundlagen/ aquaprotect/nutzungsbedingungen-aquaprotect.html (last access: 7 September 2018), 2008.

Fuchs, S., Keiler, M., and Zischg, A.: A spatiotemporal multi-hazard exposure assessment based on property data, Nat. Hazards Earth Syst. Sci., 15, 2127-2142, https://doi.org/10.5194/nhess-15-2127-2015, 2015.

Fuchs, S., Röthlisberger, V., Thaler, T., Zischg, A., and Keiler, M.: Natural Hazard Management from a Coevolutionary Perspective: Exposure and Policy Response in the European Alps, Ann. Am. Assoc. Geogr., 107, 382-392, https://doi.org/10.1080/24694452.2016.1235494, 2017.

Gerl, T., Kreibich, H., Franco, G., Marechal, D., and Schröter, K.: A Review of Flood Loss Models as Basis for Harmonization and Benchmarking, PloS one, 11, e0159791, https://doi.org/10.1371/journal.pone.0159791, 2016.

Glas, H., Jonckheere, M., Mandal, A., James-Williamson, S., Maeyer, P. de, and Deruyter, G.: A GIS-based tool for flood damage assessment and delineation of a methodology for future risk assessment: Case study for Annotto Bay, Jamaica, Nat. Hazards, 88, 1867-1891, https://doi.org/10.1007/s11069-017-2920$5,2017$.

Hägi, A.: Die Bewertung von Liegenschaften, Zürich, 224 pp., 1961.

Hatzikyriakou, A. and Lin, N.: Simulating storm surge waves for structural vulnerability estimation and flood hazard mapping, Nat. Hazards, 89, 939-962, https://doi.org/10.1007/s11069-0173001-5, 2017.

ICPR, International Commission for the Protection of the Rhine: Rhine-Atlas: Flood maps of extreme event, available at: http:// www.rheinatlas.de/ (last access: 7 September 2018), 2001.

IPCC: Climate Change 2014. Synthesis Report. Summary for Policymakers, 32 pp., 2014.

Jongman, B., Kreibich, H., Apel, H., Barredo, J. I., Bates, P. D., Feyen, L., Gericke, A., Neal, J., Aerts, J. C. J. H., and Ward, P. J.: Comparative flood damage model assessment: towards a European approach, Nat. Hazards Earth Syst. Sci., 12, 3733-3752, https://doi.org/10.5194/nhess-12-3733-2012, 2012.

Jongman, B., Koks, E. E., Husby, T. G., and Ward, P. J.: Increasing flood exposure in the Netherlands: implications for risk financing, Nat. Hazards Earth Syst. Sci., 14, 1245-1255, https://doi.org/10.5194/nhess-14-1245-2014, 2014.

Kleist, L., Thieken, A. H., Köhler, P., Müller, M., Seifert, I., Borst, D., and Werner, U.: Estimation of the regional stock of residential buildings as a basis for a comparative risk assessment in Germany, Nat. Hazards Earth Syst. Sci., 6, 541-552, https://doi.org/10.5194/nhess-6-541-2006, 2006.

Klijn, F., Baan, P., de Bruijn, K., and Kwadijk, J. C. J.: Overstromingsrisico's in Nederland in een veranderend klimaat, $165 \mathrm{pp}$., 2007.

Koivumäki, L., Alho, P., Lotsari, E., Käyhkö, J., Saari, A., and Hyyppä, H.: Uncertainties in flood risk mapping: A case study on estimating building damages for a river flood in Finland, J. Flood Risk Manag., 3, 166-183, https://doi.org/10.1111/j.1753318X.2010.01064.x, 2010.
Kundzewicz, Z. W., Kanae, S., Seneviratne, S. I., Handmer, J., Nicholls, N., Peduzzi, P., Mechler, R., Bouwer, L. M., Arnell, N., Mach, K., Muir-Wood, R., Brakenridge, G. R., Kron, W., Benito, G., Honda, Y., Takahashi, K., and Sherstyukov, B.: Flood risk and climate change: Global and regional perspectives, Hydrolog. Sci. J., 59, 1-28, https://doi.org/10.1080/02626667.2013.857411, 2014.

Liu, J., Hertel, T. W., Diffenbaugh, N. S., Delgado, M. S., and Ashfaq, M.: Future property damage from flooding: sensitivities to economy and climate change, Climatic Change, 132, 741-749, 2015.

Lowe, D. J., Emsley, M. W., and Harding, A.: Predicting Construction Cost Using Multiple Regression Techniques, J. Constr. Eng. M., 132, 750-758, https://doi.org/10.1061/(ASCE)07339364(2006)132:7(750), 2006.

Merz, B., Kreibich, H., Schwarze, R., and Thieken, A.: Review article "Assessment of economic flood damage", Nat. Hazards Earth Syst. Sci., 10, 1697-1724, https://doi.org/10.5194/nhess10-1697-2010, 2010.

Mobiliar Lab: hochwasserrisiko.ch: Beschreibung Projekt und Vorgehen, available at: http://www.hochwasserrisiko.ch/ HochwassergefaehrdungCH/Projekt.html (last access: 7 September 2018), 2016.

Molinari, D. and Scorzini, A. R.: On the Influence of Input Data Quality to Flood Damage Estimation: The Performance of the INSYDE Model, Water, 9, 688, https://doi.org/10.3390/w9090688, 2017.

Naegeli, W. and Wenger, H.: Der Liegenschaftenschätzer, 4th Edn., Schulthess, Zürich, 328 pp., 1997.

Penning-Rowsell, E., Johnson, C., Tunstall, S., Tapsel, S., Morris, J., Chatterton, J., and Green, C.: The Benefits of Flood and Coastal Risk Management: A Handbook of Assessment Techniques, 89 pp., 2005.

Penning-Rowsell, E. C.: A realistic assessment of fluvial and coastal flood risk in England and Wales, Trans. Inst. Br. Geogr., 40, 44 61, https://doi.org/10.1111/tran.12053, 2015.

Röthlisberger, V., Zischg, A. P., and Keiler, M.: Identifying spatial clusters of flood exposure to support decision making in risk management, Sci. Total Environ., 598, 593-603, https://doi.org/10.1016/j.scitotenv.2017.03.216, 2017.

Sonmez, R.: Parametric Range Estimating of Building Costs Using Regression Models and Bootstrap, J. Constr. Eng. M., 134, 1011-1016, https://doi.org/10.1061/(ASCE)07339364(2008)134:12(1011), 2008.

SVKG and SEK/SVIT: Das Schweizerische Schätzerhandbuch: Das umfassende und praxisorientierte Lehrbuch über die wichtigsten Immobilien-Bewertungsmethoden der Schweiz, 4th Edn., 382 pp., 2012.

Thieken, A. H., Müller, M., Kleist, L., Seifert, I., Borst, D., and Werner, U.: Regionalisation of asset values for risk analyses, Nat. Hazards Earth Syst. Sci., 6, 167-178, https://doi.org/10.5194/nhess-6-167-2006, 2006.

Thieken, A. H., Olschewski, A., Kreibich, H., Kobsch, S., and Merz, B.: Development and evaluation of FLEMOps - a new Flood Loss Estimation Model for the private sector, in: Flood Recovery, Innovation and Response, edited by: Proverbs, D., Brebbia, C. A., and Penning-Rowsell, E., WIT Trans. Ecol. Envir., 118, 315-324, 2008. 
van Dyck, J. and Willems, P.: Probabilistic flood risk assessment over large geographical regions, Water Resour. Res., 49, 3330 3344, https://doi.org/10.1002/wrcr.20149, 2013.

Wagenaar, D., de Jong, J., and Bouwer, L. M.: Multi-variable flood damage modelling with limited data using supervised learning approaches, Nat. Hazards Earth Syst. Sci., 17, 1683-1696, https://doi.org/10.5194/nhess-17-1683-2017, 2017.

Wagenaar, D. J., de Bruijn, K. M., Bouwer, L. M., and de Moel, H.: Uncertainty in flood damage estimates and its potential effect on investment decisions, Nat. Hazards Earth Syst. Sci., 16, 1-14, https://doi.org/10.5194/nhess-16-1-2016, 2016.

Winter, B., Schneeberger, K., Huttenlau, M., and Stötter, J.: Sources of uncertainty in a probabilistic flood risk model, Nat. Hazards, 91, 431-446, https://doi.org/10.1007/s11069-017-3135-5, 2018.
Wuertz, D.: Package "fExtremes": Description of package version 3010.81, 37 pp., 2015.

Wünsch, A., Herrmann, U., Kreibich, H., and Thieken, A. H.: The role of disaggregation of asset values in flood loss estimation: a comparison of different modeling approaches at the Mulde River, Germany, Environ. Manage., 44, 524-541, https://doi.org/10.1007/s00267-009-9335-3, 2009.

Zhai, G., Fukuzono, T., and Ikeda, S.: Modeling Flood Damage: Case of Tokai Flood 2000, J. Am. Water Resour. As., 4, 77-92, 2005. 